\title{
Evaluation of the Effect of Composition on Radiation Hardening and Embrittlement in Model FeCrAl Alloys
}

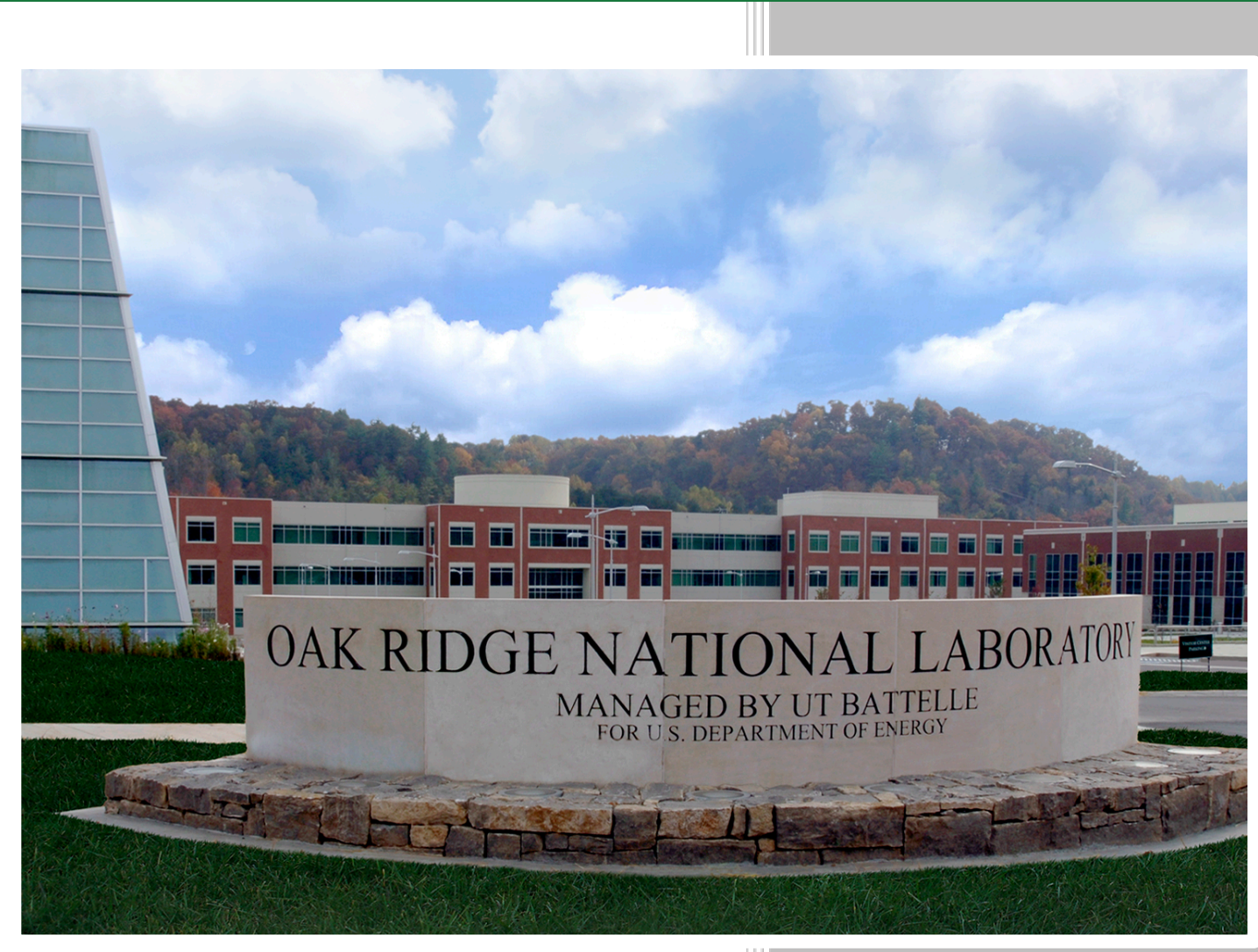

Approved for public release. Distribution is unlimited.
Kevin G. Field

Samuel A. Briggs Philip Edmondson Xunxiang $\mathrm{Hu}$ Kenneth C. Littrell Richard Howard Chad M. Parish Yukinori Yamamoto

September 18, 2015 


\section{DOCUMENT AVAILABILITY}

Reports produced after January 1, 1996, are generally available free via US Department of Energy (DOE) SciTech Connect.

Website http://www.osti.gov/scitech/

Reports produced before January 1, 1996, may be purchased by members of the public from the following source:

National Technical Information Service

5285 Port Royal Road

Springfield, VA 22161

Telephone 703-605-6000 (1-800-553-6847)

TDD 703-487-4639

Fax 703-605-6900

E-mail info@ntis.gov

Website http://www.ntis.gov/help/ordermethods.aspx

Reports are available to DOE employees, DOE contractors, Energy Technology Data Exchange representatives, and International Nuclear Information System representatives from the following source:

Office of Scientific and Technical Information

PO Box 62

Oak Ridge, TN 37831

Telephone 865-576-8401

Fax 865-576-5728

E-mail reports@osti.gov

Website http://www.osti.gov/contact.html

This report was prepared as an account of work sponsored by an agency of the United States Government. Neither the United States Government nor any agency thereof, nor any of their employees, makes any warranty, express or implied, or assumes any legal liability or responsibility for the accuracy, completeness, or usefulness of any information, apparatus, product, or process disclosed, or represents that its use would not infringe privately owned rights. Reference herein to any specific commercial product, process, or service by trade name, trademark, manufacturer, or otherwise, does not necessarily constitute or imply its endorsement, recommendation, or favoring by the United States Government or any agency thereof. The views and opinions of authors expressed herein do not necessarily state or reflect those of the United States Government or any agency thereof. 
ORNL/TM-2015/518

M2FT- 15OR02302243

Fuel Cycle Research and Development (FCRD)

\section{Evaluation of the Effect of Composition on Radiation Hardening and Embrittlement in Model FeCrAl Alloys}

Kevin G. Field, Samuel A. Briggs, Philip Edmondson, Xunxiang Hu, Kenneth C. Littrell, Richard Howard, Chad M. Parish, and Yukinori Yamamoto

Date Published: September $18^{\text {th }}, 2015$

Prepared by

OAK RIDGE NATIONAL LABORATORY

Oak Ridge, Tennessee 37831-6283

managed by

UT-BATTELLE, LLC

for the

US DEPARTMENT OF ENERGY

under contract DE-AC05-00OR22725 



\section{CONTENTS}

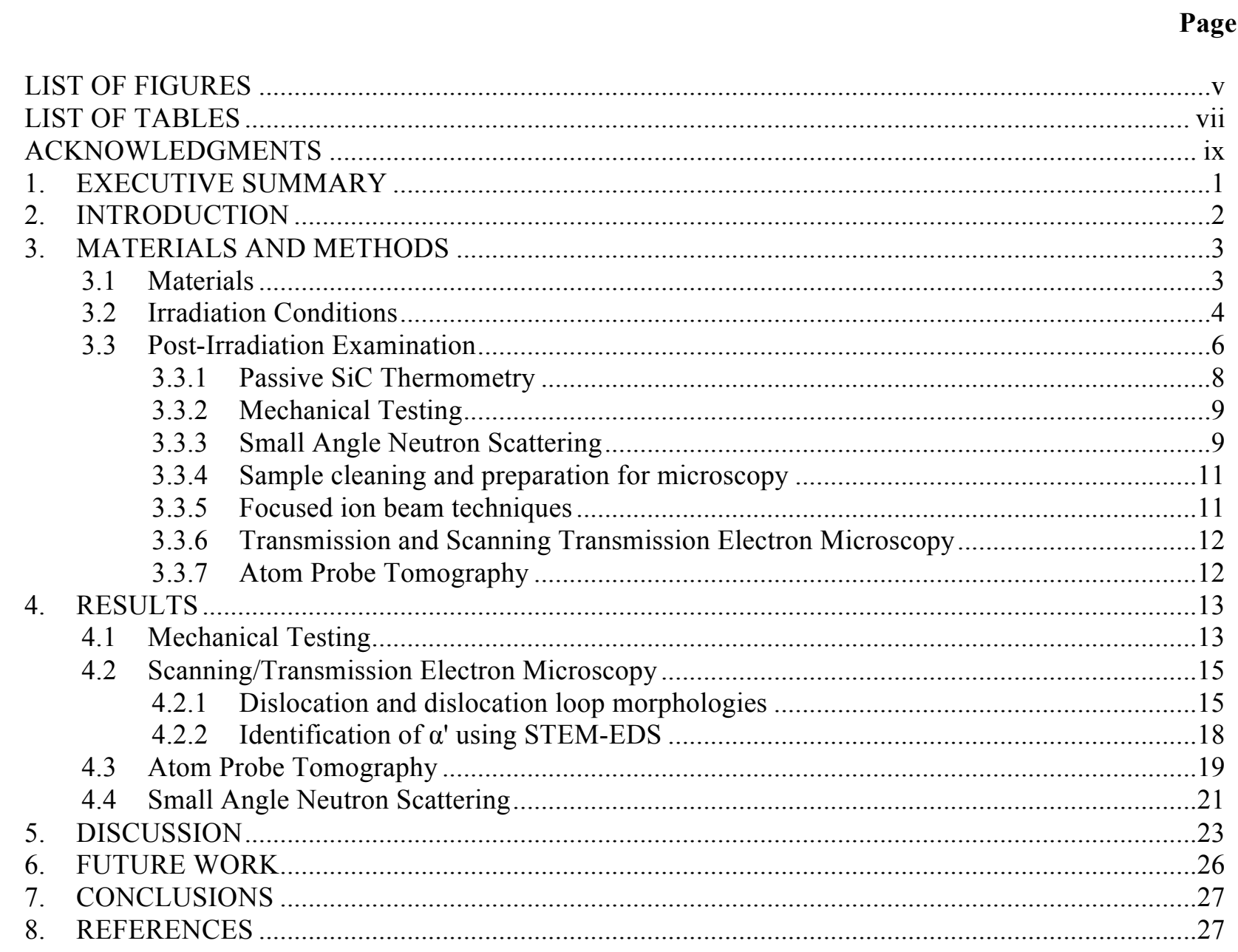





\section{LIST OF FIGURES}

Figure

Page

Figure 1: Simplified schematic of the SS-J2 tensile specimen geometry for HFIR irradiations.

Figure not to scale.

Figure 2: Simplified schematic cross-section through HFIR illustrating the primary experimental sites (left) and a picture of the reactor core (right)...

Figure 3: Schematic of irradiation targets loaded with 36 tensile specimens and inserted into the flux trap of HFIR.

Figure 4: Coefficient of thermal expansion as a function of temperature for a passive $\mathrm{SiC}$ thermometry sample for the FCAY3 irradiation target and software analysis output.

Figure 5: Example of raw data collected on the GP-SANS line at ORNL for two detector settings for the Alkrothal 720 specimen irradiated to $0.3 \mathrm{dpa}$ at $335^{\circ} \mathrm{C}$.....

Figure 6: Example of reduced data placed on the $\mathrm{cm}^{-1}$ absolute scale and fit model for the data presented in Figure 5.

Figure 7: SEM micrograph of prepared samples using FIB preparation techniques, a) a S/TEM electron transparent foil and b) a APT sharpened tip.

Figure 8: Engineering stress-strain curves for all alloys before irradiation (black lines) and after irradiation (colored lines).

Figure 9: Stitched bright field STEM image showing dislocation loops near a random high angle grain boundary irradiated to $1.8 \mathrm{dpa}, 320^{\circ} \mathrm{C}$ in a Alkrothal 720 sample

Figure 10: Outputted image based on specialized data analysis procedure showing identified dislocation loops from Figure 9. Red loops indicate either edge-on or in-plane a100 loops, blue loops indicate a2111 loops, green loops indicate unidentifiable defects (mostly black dots) while light yellow lines indicate $100 \mathrm{~nm}$ size bins uniformly spaced away from the grain boundary (dashed black line).

Figure 11: Dark-field STEM image, $x$-ray maps, and color overlay maps derived from a spectrum image on the $1.8 \mathrm{dpa}, 320^{\circ} \mathrm{C}$ irradiated Alkrothal 720 alloy showing $\alpha^{\prime}$ and RIS at a grain boundary. Cr-rich $\alpha^{\prime}$ is observed as clustering the $\mathrm{Cr}$ map and as green dots in the overlay map. .....

Figure 12: Reconstructed microtip of $7.0,320^{\circ} \mathrm{C}$ irradiated $\mathrm{Fe}-18 \mathrm{Cr}-2.9 \mathrm{Al}$ showing $\mathrm{Cr}$-rich clusters using 30 at $\%$ concentration isosurfaces.

Figure 13: Scattered intensities of model $\mathrm{FeCrAl}$ specimens obtained from SANS after irradiation, (a) for the Fe-19Cr-2.9Al with changing irradiation conditions and (b) for constant irradiation conditions but varying alloy content in the model $\mathrm{FeCrAl}$ alloys.

Figure 14: Trends on size and number density of $\alpha^{\prime}$ precipitates as a function of irradiation dose as determined by SANS.....

Figure 15: Comparison of SANS results with those published in literature. Green polygon is based on the data presented in Table 10. Blue lines indicate established trends from aged FeCrAl alloys [29]. All other literature results complied from [26, 30-32, 38-42].

Figure 16: Predicted change in ductile to brittle transition temperature for irradiated $\mathrm{FeCrAl}$ based on an empirically established relationship and it's alignment with the observed change in yield stress. 



\section{LIST OF TABLES}

Table

Page

Table 1: Summary of FeCrAl alloy compositions in weight percent (wt.\%). ..........................................

Table 2: Determined irradiation conditions for each irradiation target...................................................5

Table 3: Summary of completed PIE on each alloy per irradiation condition. Green checks indicate that at least preliminary work is completed, blue circles indicates that the work is tentatively planned or in progress, and red x's indicates work is not scheduled.......................

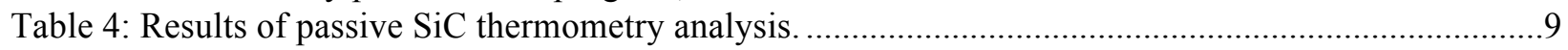

Table 5: Summary of mechanical properties of unirradiated and irradiated specimens............................14

Table 6: Summary of average size and number density of STEM-identified defects in Generation I $\mathrm{FeCrAl}$ specimens irradiated in the HFIR reactor at $1.8 \mathrm{dpa}, 382^{\circ} \mathrm{C}$. Reproduced from [11].

Table 7: Summary of quantified number densities for different dislocation loop types for specific grain boundaries in the $1.8 \mathrm{dpa}, 320^{\circ} \mathrm{C}$ irradiated Alkrothal 720 sample.

Table 8: Summary of $\alpha$ ' precipitation behavior vs. FeCrAl composition.

Table 9: Summary of $\alpha^{\prime}$ precipitation behavior vs. nominal damage dose.

Table 10: Summary of Cr-rich $\alpha^{\prime}$ size and number density determined using SANS in FeCrAl specimens irradiated in the HFIR reactor. Data for the $1.8 \mathrm{dpa}, 382^{\circ} \mathrm{C}$ from Field et al. [11] 



\section{ACKNOWLEDGMENTS}

The authors would like to thank the Irradiated Materials Examination and Testing facilitiy, the Low Activation Materials Development and Analysis laboratory, and the Center for Advanced Energy Studies staff for their continuing support of this research.

Research was sponsored by DOE Office of Nuclear Energy, Advanced Fuel Campaign of the Fuel Cycle R\&D program. Research on the CG-2 General Purpose SANS and neutron irradiation of FeCrAl alloys at ORNL's HFIR user facility was sponsored by the Scientific User Facilities Division, Office of Basic Energy Sciences, DOE. Transmission electron microscopy and atom probe tomography was partially sponsored by ORNL's Center for Nanophase Materials Sciences, which is sponsored by the Scientific User Facilities Division, Office of Basic Energy Sciences, DOE. This research was performed, in part, using instrumentation (FEI Talos F200X TEM) provided by the Department of Energy, Office of Nuclear Energy, Fuel Cycle R\&D Program, and the Nuclear Science User Facilities. Funding for SAB was provided by the DOE Office of Nuclear Energy's Nuclear Energy University Programs. 


\section{EXECUTIVE SUMMARY}

This report details the findings of post-radiation mechanical testing and microstructural characterization performed on a series of model and commercial FeCrAl alloys to assist with the development of a cladding technology with enhanced accident tolerance. The samples investigated include model alloys with simple ferritic grain structure and two commercial alloys with minor solute additions. These samples were irradiated in the High Flux Isotope Reactor (HFIR) at Oak Ridge National Laboratory (ORNL) up to nominal doses of 7.0 dpa near or at Light Water Reactor (LWR) relevant temperatures $\left(300-400^{\circ} \mathrm{C}\right)$. Characterization included a suite of techniques including small angle neutron scattering (SANS), atom probe tomography (APT), and transmission based electron microscopy techniques. Mechanical testing included tensile tests at room temperature on sub-sized tensile specimens.

The goal of this work was to conduct detailed characterization and mechanical testing to begin establishing empirical and/or theoretical structure-property relationships for radiation-induced hardening and embrittlement in the $\mathrm{FeCrAl}$ alloy class. Development of such relationships will provide insight on the performance of $\mathrm{FeCrAl}$ alloys in an irradiation environment and will enable further development of the alloy class for applications within a LWR environment. A particular focus was made on establishing trends, including composition and radiation dose.

The report highlights in detail the pertinent findings based on this work. This report shows that radiation hardening in the alloys is primarily composition dependent due to the phase separation in the high-Cr $\mathrm{FeCrAl}$ alloys. Other radiation induced/enhanced microstructural features were less dependent on composition and when observed at low number densities, were not a significant contributor to the observed mechanical responses. Pre-existing microstructure in the alloys was found to be important, with grain boundaries and pre-existing dislocation networks acting as defect sinks, resulting in variations in the observed microstructures after irradiation. Dose trends were also observed, with increasing radiation dose promoting changes in the size and number density of the Cr-rich $\alpha^{\prime}$ precipitates. Based on the microstructural analysis, performed tensile testing, and prior knowledge from $\mathrm{FeCr}$ literature it was hypothesized that the formation of the Cr-rich $\alpha^{\prime}$ precipitates could lead to significant radiation-induced embrittlement in the alloys, and this could be composition dependent, a result which would mirror the trends observed for radiation-induced hardening. Due to the limited database on embrittlement in the $\mathrm{FeCrAl}$ alloy class after irradiation, a series of radiation experiments have been implemented.

The overarching point of view within this report is the radiation tolerance of FeCrAl is complex, with many mechanisms and factors to be considered at once. Further development of the FeCrAl alloy class for enhanced accident tolerant applications requires detailed, single (or at least limited) variable experiments to fully comprehend and predict the performance of this alloy in LWRs.

This report has been submitted as fulfillment of milestone M2FT-15OR02302243 titled, "Summary report on the effect of composition on the irradiation embrittlement of Gen 1 ATF FeCrAl" for the Department of Energy Office of Nuclear Energy, Advanced Fuel Campaign of the Fuel Cycle R\&D program. 


\section{INTRODUCTION}

Accident tolerant fuel-clad systems or systems with enhanced accident tolerance for light water reactors (LWRs) have become of interest in the past half-a-decade due to the nuclear accident that occurred in Japan in 2011. Many different fuel-clad systems have been proposed with most of them centered on the replacement of the typical $\mathrm{Zr}$-based clad- $\mathrm{UO}_{2}$ system to increase the claddings' high temperature steam oxidation resistance and hence providing greater safety margins [1]. One clad of particular interest is $\mathrm{FeCrAl}$ alloys with minor $\mathrm{Y}$ additions as this class of alloy has exhibited high temperature steam oxidation up to $1450^{\circ} \mathrm{C}$, thereby increasing overall safety margins by limiting the heat and hydrogen production during high temperature steam exposures [2-4]. Furthermore, FeCrAl alloys could be designed to retain superior high temperature strength compared to Zr-based alloys allowing for enhanced burst margins during design basis accident scenarios.

Current research and development efforts have focused on optimizing the alloy composition to develop a robust, nuclear-grade $\mathrm{FeCrAl}$ alloy. As such, the composition must be optimized to maintain high temperature steam oxidation while still exhibiting properties conducive to normal operation in either a pressurized water reactor (PWR) or boiling water reactor (BWR). Such properties include high temperature mechanical performance, corrosion resistance, formability, thermal stability, and irradiation performance.

Irradiation performance is a key factor for successful development of $\mathrm{FeCrAl}$ clad with enhanced accident tolerance as poor irradiation performance could lead to severe changes in microstructure and mechanical properties leading to poor performance or even failure during normal operation or during accident type scenarios. To evaluate this key variable, a series of irradiation tests have either occurred, are in the process, or currently being designed with specific marks to be evaluated such as radiation hardening, radiation embrittlement, irradiated tube performance, and so on. The main topic of this report is the evaluation of the radiation hardening and possible embrittlement in select FeCrAl alloys and an evaluation of the key microstructural changes contributing to the observed responses as a function of changing composition for FeCrAl alloys.

The development of FeCrAl alloys for enhanced accident tolerance at Oak Ridge National Laboratory (ORNL) has followed a phased approach where Phase I consisted of exploring the composition space of FeCrAl-Y alloy compositions for fundamental properties. These alloys are also regarded as Generation I or model $\mathrm{FeCrAl}$ alloys within reporting [5-13]. Activities using Phase I alloys have shown higher $\mathrm{Cr}$ additions would be better for corrosion and/or oxidation resistance to support the stability of the aluminascale formation under high temperature steam exposures but could increase the formation of the $\mathrm{Cr}$-rich $\alpha^{\prime}$ precipitates due to the miscibility gap in the $\mathrm{FeCr}$ and $\mathrm{FeCrAl}$ phase diagrams [2-4]. Weldability of the Phase I alloys was shown to be straight forward, with little effect of composition on the weldments of $\mathrm{FeCrAl}$ alloys using controlled fusion welding techniques [12]. Preliminary reporting on irradiation performance of Phase I alloys showed irradiation could accelerate the formation of the Cr-rich $\alpha^{\prime}$ and create dislocation loops in the microstructure leading to radiation hardening but only one irradiation dose and temperature was evaluated [11].

Based on the overall Phase I/Generation I evaluations, Phase II alloys (or Generation II/engineering alloy) were initiated based on a Fe-13Cr-4.5Al-0.05Y down selected composition [6]. Minor alloying additions were applied through guidance from computational thermodynamics for improved strengths together with sufficient oxidation resistance at elevated temperatures, without sacrificing good fabricability to support $\mathrm{FeCrAl}$ thin-wall tube product with commercial manufacturers. The comprehensive summary of the Generation II ATF FeCrAl alloy development and property evaluation can be found in the reports previously published $[6,7,14,15]$. For more information on the overarching program centered on 
developing accident tolerant $\mathrm{FeCrAl}$ alloys the reader is referred to the Technology Implementation Plan ATF FeCrAl Cladding for LWR Application, ORNL/TM-2014/353 [13].

The objective of this report is to summarize the recent progress on the Generation I FeCrAl cladding developing with respect to the irradiation performance with key outlooks on the radiation hardening and embrittlement in select alloys based on composition variations. Inline with this evaluation is the evaluation of commercially available $\mathrm{FeCrAl}$ alloys that have been evaluated to serve as a litmus test for the Generation I alloy development. Due to the lead times on executing radiation experiments, Generation II alloy development, as discuss previously, has already been initiated but the reporting on Generation I still guides and assists within the current alloy development efforts. The current evaluation efforts have focused on developing structure-property relationship(s) by using advanced characterization efforts such as atom probe tomography (APT), small angle neutron scattering (SANS), and scanning transmission electron microscopy (STEM) coupled with mechanical testing of sub-sized tensile specimens. Established models and empirical models were used to develop the structure-property relationships reported here.

\section{MATERIALS AND METHODS}

\subsection{Materials}

The alloys selected for this study are Generation I FeCrAl model alloys with minor Y additions and two commercial FeCrAl alloys. Here, Generation I is a designation for ORNL developed FeCrAl model alloys that have known oxidation resistance and were developed to provide information on the composition effects for a range of material properties. For more information on the designation tied to a Generation I alloys, the reader is referred to the Technology Implementation Plan ATF FeCrAl Cladding for LWR Application, ORNL/TM-2014/353 [13]. Details on the fabrication and base microstructure of the Generation I FeCrAl alloys have previously been reported [10]. The chemical composition for each alloy studied can be found in Table 1. All investigated Generation I FeCrAl alloys had a grain size of 20-50 $\mu \mathrm{m}$ and were cold rolled to a $10 \%$ thickness reduction to simulate the potential cold-shaping process route for seamless fuel cladding tube production.

Table 1: Summary of FeCrAl alloy compositions in weight percent (wt.\%).

\begin{tabular}{lcccccccccc}
\hline \multirow{2}{*}{ Alloy } & \multicolumn{10}{c}{ Composition (wt \%) } \\
\cline { 2 - 11 } & Fe & Cr & Al & Y & C & S & O & N & P & Si \\
\hline \hline Fe-10Cr-4.8Al & 85.15 & 10.01 & 4.78 & 0.038 & 0.005 & 0.001 & 0.0013 & 0.0003 & 0.006 & $<0.01$ \\
Fe-12Cr-4.4Al & 83.56 & 11.96 & 4.42 & 0.027 & 0.005 & 0.0013 & 0.0017 & 0.0009 & 0.0 & 0.01 \\
Fe-15Cr-3.9Al & 80.99 & 15.03 & 3.92 & 0.035 & 0.005 & 0.0004 & 0.0025 & 0.0007 & $<0.002$ & 0.01 \\
Fe-18Cr-2.9Al $^{1}$ & 79.52 & 17.51 & 2.93 & 0.017 & 0.005 & 0.0006 & 0.0015 & 0.0011 & $<0.002$ & $<0.01$ \\
APMT $^{1}$ & 69.01 & 21.64 & 4.93 & 0.120 & 0.03 & $<0.001$ & 0.494 & 0.0504 & 0.01 & $<0.001$ \\
K720 $^{2}$ & 81.36 & 12.95 & 4.21 & 0.0 & 0.034 & 0.0015 & 0.0018 & 0.0074 & 0.008 & 0.3 \\
\hline
\end{tabular}

${ }^{1}$ Addtional elements: Co: 0.02, Cu: 0.04, Hf: 0.16, Mn: 0.1, Mo: 2.77, Nb: 0.02, Ni: 0.12, Ti: 0.02, V: 0.04, Zr: 0.1, all in wt \%

${ }^{2}$ Addtional elements: Co: 0.02, Cu: 0.01, Mn: 0.44, Ni: 0.12, Ti: 0.44 , V: $0.03, \mathrm{Zr}: 0.06$, all in wt \%

Along with the Generation I model FeCrAl alloys, two commercial alloys were selected. The first was Kanthal APMT which is a $22 \mathrm{wt} . \% \mathrm{Cr} \mathrm{FeCrAl}$ alloy with oxide dispersions that have seen interest in the fossil fuel energy sector. The other is Alkrothal 720 (K720) that is a 13 wt.\% Cr FeCrAl alloy with minor solute additions. These alloys were investigated to provide a comparison between the simple-ferritic $\mathrm{FeCrAl}$ alloys of the Generation I alloys and more complex commercial alloys that contain minor and tramp elements. 
All selected samples were machined to form SS-J2 flat sheet-type "dog-bone" tensile specimens. This geometry has been used extensively in HFIR materials testing programs enabling direct comparisons between the work presented here and those presented in literature. Figure 1 shows a simplified schematic of the SS-J2 specimen. The SS-J2 specimen was selected as it minimizes the total specimen volume while still providing reasonable tensile test results pre- and post-irradiation. Reduced volumes are needed to minimize sample activity. Furthermore, the sheet type specimen allows for efficient stacking within the irradiation capsule geometry and provides effective heat transfer across the stacked faces during irradiation. Here, SS-J2 specimens without pinholes were selected. The elimination of the pinhole provides more volume for materials characterization sample preparation such as focused ion beam (FIB) preparation and allows for easier loading into the tensile test frame using typical hot cell manipulator configurations.

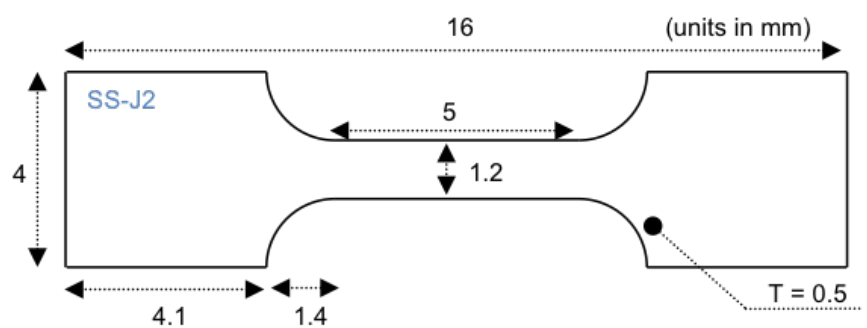

Figure 1: Simplified schematic of the SS-J2 tensile specimen geometry for HFIR irradiations. Figure not to scale.

\subsection{Irradiation Conditions}

All samples were irradiated in the HFIR which is a beryllium-reflected, pressurized, light-water-cooled and moderated flux-trap-type reactor. The core consists of aluminum-clad involute-fuel plates, which currently utilizes highly enriched ${ }^{235} \mathrm{U}$ fuel at a power level of $85 \mathrm{MWt}$. The reactor core, illustrated in Figure 2, consists of two concentric annular regions, each approximately $61 \mathrm{~cm}$ in height. The flux trap is $\sim 12.7 \mathrm{~cm}$ in diameter, and the outer fueled region is $\sim 43.5 \mathrm{~cm}$ in diameter. The fuel region is surrounded by a beryllium annular reflector approximately $30.5 \mathrm{~cm}$ in thickness. A water reflector of effectively infinite thickness in turn backs up the beryllium reflector. In the axial direction, the reactor is reflected by water. The reactor core assembly is contained in a $2.44 \mathrm{~m}$ diameter pressure vessel, which is located in a $5.5 \mathrm{~m}$ cylindrical pool of water.

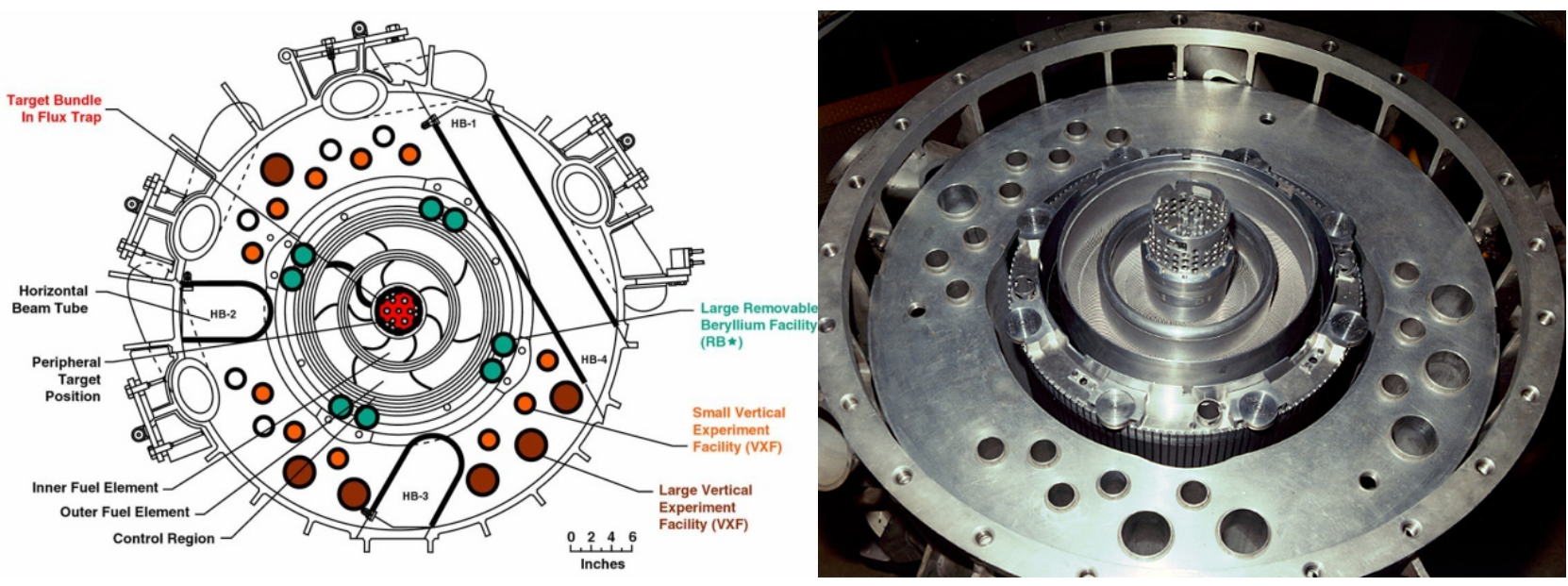

Figure 2: Simplified schematic cross-section through HFIR illustrating the primary experimental sites (left) and a picture of the reactor core (right). 
Samples were loaded into five irradiation targets, a schematic of one of the irradiation targets is provided in Figure 3. These targets were designed to house 36 of the SS-J2 specimens, gray geometries in Figure 3, each. Targets also included 12 passive $\mathrm{SiC}$ thermometry samples, tan geometries in Figure 3. Passive $\mathrm{SiC}$ thermometry is added as a means to validate the modeled target irradiation temperatures have been met. The passive $\mathrm{SiC}$ thermometry is arranged to allow for determination of axial and radial temperature gradients during irradiation. The tensile specimens are fitted with stainless steel chevrons to provide equal heat generation and heat transfer within the gage length. The specimens, SiC thermometry, and stainless steel components are contained within 3 sub-assemblies to facilitate ease of target deconsolidation during PIE activities. The primary outer containment is an Al6061 tube. The target was backfilled with He gas after loading the sub-assemblies into the outer housing to facilitate efficient heat transfer during irradiation. The result is all samples used in this study were irradiated in an inert atmosphere.

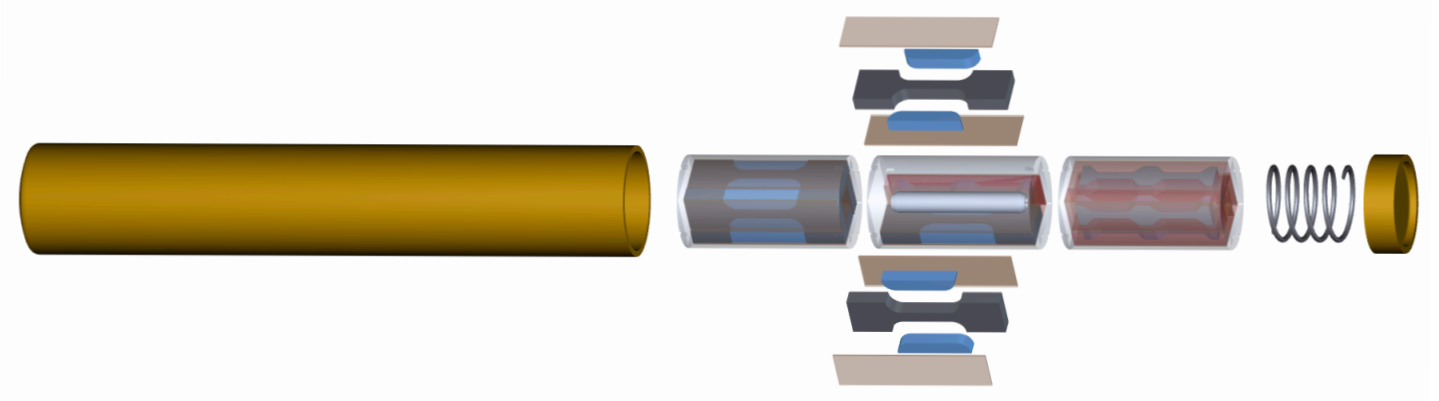

Figure 3: Schematic of irradiation targets loaded with 36 tensile specimens and inserted into the flux trap of HFIR

Loaded irradiation targets were inserted into the central flux trap of the HFIR; position within the flux trap depended on the target irradiation dose. Pre-defined neutron fluences were provided to HFIR staff to coordinate insertion and ejection of samples from the HFIR core. For two of the samples, the desired irradiation dose was lower than the typical accumulated dose (dpa) for a single cycle in a target position in the HFIR and hence was irradiated using the hydraulic tube (HT) facility. After irradiation, the total time of irradiation was determined and reported. Based on the irradiation time and known capsule average neutron flux per target position, the total accumulated neutron fluence was calculated. Neutron fluence was converted to dpa using conversions based on the SCEPTER code. A summary of the completed irradiation campaign is provided in Table 2 . Note, the full details for the FCAY5 irradiation target are not provided as this target has finished being irradiated but has not had calculations completed to provide shipment to the hot cell facilities and hence the final fluence, dose rate, and dose have yet to be determined.

Table 2: Determined irradiation conditions for each irradiation target

\begin{tabular}{lccccccc}
\hline $\begin{array}{c}\text { Capsule } \\
\text { ID }\end{array}$ & $\begin{array}{c}\text { HFIR } \\
\text { Position }\end{array}$ & $\begin{array}{c}\text { Target } \\
\text { Temperature } \\
\left({ }^{\circ} \mathbf{C}\right)\end{array}$ & $\begin{array}{c}\text { Exposure } \\
\text { Time (hrs) }\end{array}$ & $\begin{array}{c}\text { Flux }\left(\mathbf{n} / \mathbf{c m}^{2} \mathbf{s}\right) \\
{[\mathbf{E}>. \mathbf{1 ~ M e V}]}\end{array}$ & $\begin{array}{c}\text { Fluence } \\
\left(\mathbf{n} / \mathbf{c m}^{\mathbf{2}}\right) \\
{[\mathbf{E}>.1} \\
\mathbf{M e V}]\end{array}$ & $\begin{array}{c}\text { Dose } \\
\text { Rate } \\
(\mathbf{d p a} / \mathbf{s})\end{array}$ & $\begin{array}{c}\text { Dose } \\
(\mathbf{d p a})\end{array}$ \\
\hline \hline FCAY1 & HT & 320 & 120 & $8.54 \times 10^{14}$ & $3.69 \times 10^{20}$ & $7.7 \times 10^{-7}$ & 0.3 \\
FCAY2 & HT & 320 & 301 & $8.54 \times 10^{14}$ & $9.25 \times 10^{20}$ & $7.7 \times 10^{-7}$ & 0.8 \\
FCAY3 & THT-2 & 320 & 614 & $8.84 \times 10^{14}$ & $1.95 \times 10^{21}$ & $8.1 \times 10^{-7}$ & 1.8 \\
FCAY4 & PTP-7 & 320 & 2456 & $8.74 \times 10^{14}$ & $7.73 \times 10^{21}$ & $7.9 \times 10^{-7}$ & 7.0 \\
FCAY5 & PTP-7 & 320 & TBD & $8.74 \times 10^{14}$ & TBD & TBD & TBD \\
\hline
\end{tabular}




\subsection{Post-Irradiation Examination}

Irradiation targets were allowed to reduce in activity in the reactor pool of HFIR for a minimum of 30 days before transferring to the IMET facility at ORNL. As irradiation times for each capsule varied, only the first three targets (FCAY1-3) were shipped together. All other targets were shipped individually after completing the desired neutron fluence. Targets were opened using a slow speed saw configured for the work at the Irradiated Materials Examination and Testing (IMET) hot cell facilities. After sectioning on both ends, the interior cans were pushed out of the outer housing using a specialized jig and then samples were removed from the sub-assembly, identified, and sorted into individual storage containers. SiC thermometry was also identified and sorted. For the FCAY4 capsule, care was taken with the SiC thermometry to identify the location of where the thermometry was removed, i.e. from the top, middle, or bottom sub-assembly shown in Figure 3. SiC thermometry was shipped to ORNL's Low Activation Materials Development and Analysis (LAMDA) facility to determine the nominal irradiation temperature for each irradiation target. Single samples of each alloy were selected from each irradiation target and then held for mechanical testing. All remaining samples were packaged and held as archival material for future testing.

Primary microstructural analysis was completed on broken tensile heads of each specimen in ORNL's LAMDA facility. In particular, microstructural analysis included transmission electron microscopy, scanning transmission electron microscopy (S/TEM), atom probe tomography (APT), and small angle neutron scattering (SANS). Details on the methods for these analysis techniques are provided in Sections 3.3.3-3.3.7. Due to these techniques being inherently time intensive, not all samples have completed full examination using every technique, although it is anticipated most if not all samples will undergo characterization. Table 3 summarizes the completed to-date post-irradiation examination (PIE) per alloy and irradiation condition, for reference. The most extensive characterization has been completed on the samples from the FCAY3 irradiation target while samples from other irradiation targets have been evaluated but have not fully completed every PIE technique. 
Table 3: Summary of completed PIE on each alloy per irradiation condition. Green checks indicate that at least preliminary work is completed, blue circles indicates that the work is tentatively planned or in progress, and red $x$ 's indicates work is not scheduled.

\begin{tabular}{|c|c|c|c|c|c|c|c|c|c|c|c|c|c|c|}
\hline Sample & Target & Condition & $\begin{array}{c}\text { Samples } \\
\text { out of } \\
\text { HFIR }\end{array}$ & $\begin{array}{l}\text { Samples } \\
\text { in IMET }\end{array}$ & $\begin{array}{c}\text { Samples } \\
\text { in } \\
\text { LAMDA }\end{array}$ & $\begin{array}{c}\text { SiC } \\
\text { Therm. }\end{array}$ & $\begin{array}{c}\text { RT } \\
\text { Mech. } \\
\text { Prop. }\end{array}$ & $\begin{array}{c}\text { HT } \\
\text { Mech. } \\
\text { Prop. }\end{array}$ & SANS & $\begin{array}{c}\text { TEM } \\
\text { samples } \\
\text { made }\end{array}$ & $\begin{array}{c}\text { APT } \\
\text { samples } \\
\text { made }\end{array}$ & $\begin{array}{c}\text { Disl. } \\
\text { Analysis } \\
\text { Completed }\end{array}$ & $\begin{array}{c}\text { APT } \\
\text { Analysis } \\
\text { Completed }\end{array}$ & $\begin{array}{c}\text { RIS } \\
\text { Analysis } \\
\text { Completed }\end{array}$ \\
\hline $\begin{array}{c}\mathrm{Fe}- \\
10 \mathrm{Cr}- \\
4.8 \mathrm{Al} \\
\end{array}$ & $\mathrm{n} / \mathrm{a}$ & As-rec. $(10 \% \mathrm{CW})$ & $\mathrm{n} / \mathrm{a}$ & $\mathrm{n} / \mathrm{a}$ & $\checkmark$ & $\mathrm{n} / \mathrm{a}$ & $\checkmark$ & o & $\checkmark$ & $\checkmark$ & o & $\checkmark$ & o & $*$ \\
\hline $\begin{array}{c}\mathrm{Fe}- \\
12 \mathrm{Cr}- \\
4.4 \mathrm{Al} \\
\end{array}$ & $\mathrm{n} / \mathbf{a}$ & As-rec. $(10 \% \mathrm{CW})$ & $\mathrm{n} / \mathrm{a}$ & $\mathrm{n} / \mathrm{a}$ & $\checkmark$ & $\mathrm{n} / \mathrm{a}$ & $\checkmark$ & o & $\checkmark$ & $\checkmark$ & o & $\checkmark$ & o & * \\
\hline $\begin{array}{c}\mathrm{Fe}- \\
18 \mathrm{Cr}- \\
2.9 \mathrm{Al} \\
\end{array}$ & $\mathrm{n} / \mathrm{a}$ & As-rec. $(10 \% \mathrm{CW})$ & $\mathrm{n} / \mathrm{a}$ & $n / a$ & $v$ & $\mathrm{n} / \mathrm{a}$ & $\checkmark$ & o & $v$ & $v$ & $v$ & $\checkmark$ & $\checkmark$ & * \\
\hline APMT & $\mathrm{n} / \mathrm{a}$ & As-received & $\mathrm{n} / \mathrm{a}$ & $\mathrm{n} / \mathrm{a}$ & $v$ & $\mathrm{n} / \mathrm{a}$ & $v$ & o & $\checkmark$ & $\checkmark$ & o & o & * & * \\
\hline K720 & $\mathrm{n} / \mathrm{a}$ & As-received & $\mathrm{n} / \mathrm{a}$ & $\mathrm{n} / \mathrm{a}$ & 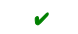 & $\mathrm{n} / \mathrm{a}$ & $\checkmark$ & o & $\checkmark$ & $\checkmark$ & o & o & * & * \\
\hline $\begin{array}{c}\mathrm{Fe}- \\
12 \mathrm{Cr}- \\
4.4 \mathrm{Al} \\
\end{array}$ & FCAY-1 & $0.3 \mathrm{dpa}, 335^{\circ} \mathrm{C}$ & $\checkmark$ & $\sigma$ & $\checkmark$ & $\checkmark$ & $v$ & o & $v$ & $v$ & 0 & o & $*$ & o \\
\hline $\begin{array}{c}\text { Fe- } \\
15 \mathrm{Cr}- \\
3.9 \mathrm{Al}\end{array}$ & FCAY-1 & $0.3 \mathrm{dpa}, 335^{\circ} \mathrm{C}$ & $\boldsymbol{v}$ & $v$ & $v$ & $v$ & $v$ & o & 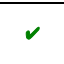 & $v$ & o & o & * & o \\
\hline K720 & FCAY-1 & $0.3 \mathrm{dpa}, 335^{\circ} \mathrm{C}$ & $\checkmark$ & $\checkmark$ & $\checkmark$ & $\checkmark$ & $\checkmark$ & o & $v$ & $*$ & o & o & * & * \\
\hline $\begin{array}{c}\mathrm{Fe}- \\
10 \mathrm{Cr}- \\
4.8 \mathrm{Al} \\
\end{array}$ & FCAY-2 & $0.8 \mathrm{dpa}, 355^{\circ} \mathrm{C}$ & $v$ & $v$ & $v$ & $\checkmark$ & $v$ & 0 & $v$ & $v$ & o & 0 & * & o \\
\hline $\begin{array}{c}\mathrm{Fe}- \\
18 \mathrm{Cr}- \\
2.9 \mathrm{Al} \\
\end{array}$ & FCAY-2 & $0.8 \mathrm{dpa}, 355^{\circ} \mathrm{C}$ & $v$ & $\checkmark$ & $v$ & $v$ & $v$ & o & $v$ & $v$ & $v$ & o & * & o \\
\hline APMT & FCAY-2 & $0.8 \mathrm{dpa}, 355^{\circ} \mathrm{C}$ & $\checkmark$ & $\checkmark$ & $\checkmark$ & $\checkmark$ & $\checkmark$ & o & $\checkmark$ & $\boldsymbol{*}$ & * & * & $*$ & * \\
\hline $\begin{array}{c}\mathrm{Fe}- \\
10 \mathrm{Cr}- \\
4.8 \mathrm{Al} \\
\end{array}$ & FCAY-3 & $1.8 \mathrm{dpa}, 382{ }^{\circ} \mathrm{C}$ & $v$ & $v$ & 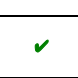 & $\checkmark$ & $\checkmark$ & 0 & $\checkmark$ & $\checkmark$ & 0 & $v$ & o & o \\
\hline $\begin{array}{c}\mathrm{Fe}- \\
12 \mathrm{Cr}- \\
4.4 \mathrm{Al} \\
\end{array}$ & FCAY-3 & $1.8 \mathrm{dpa}, 382{ }^{\circ} \mathrm{C}$ & $v$ & 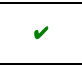 & $v$ & $v$ & $v$ & o & $v$ & $v$ & o & $v$ & o & o \\
\hline $\begin{array}{c}\text { Fe- } \\
15 \mathrm{Cr}- \\
3.9 \mathrm{Al} \\
\end{array}$ & FCAY-3 & $1.8 \mathrm{dpa}, 382{ }^{\circ} \mathrm{C}$ & $\sigma$ & $\sigma$ & $v$ & $v$ & 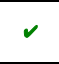 & o & $\checkmark$ & $v$ & 0 & $\sigma$ & o & o \\
\hline APMT & FCAY-3 & $1.8 \mathrm{dpa}, 382{ }^{\circ} \mathrm{C}$ & $\checkmark$ & $\checkmark$ & $\checkmark$ & $\checkmark$ & $\checkmark$ & o & $\checkmark$ & $v$ & $\checkmark$ & $\checkmark$ & o & * \\
\hline K720 & FCAY-3 & $1.8 \mathrm{dpa}, 382^{\circ} \mathrm{C}$ & $v$ & $\checkmark$ & $\checkmark$ & $\checkmark$ & $\checkmark$ & o & $v$ & $\checkmark$ & o & * & o & * \\
\hline $\begin{array}{c}\mathrm{Fe}- \\
10 \mathrm{Cr}- \\
4.8 \mathrm{Al} \\
\end{array}$ & FCAY -4 & $7.0 \mathrm{dpa}, 320^{\circ} \mathrm{C}$ & $v$ & 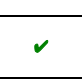 & $\checkmark$ & $\checkmark$ & $\checkmark$ & o & $\checkmark$ & o & $v$ & o & $\checkmark$ & o \\
\hline $\begin{array}{c}\mathrm{Fe}- \\
12 \mathrm{Cr}- \\
4.4 \mathrm{Al}\end{array}$ & FCAY-4 & $7.0 \mathrm{dpa}, 320^{\circ} \mathrm{C}$ & $v$ & $v$ & $v$ & $v$ & $v$ & o & $v$ & $v$ & $v$ & 0 & $v$ & $\checkmark$ \\
\hline $\begin{array}{c}\mathrm{Fe}- \\
15 \mathrm{Cr}- \\
3.9 \mathrm{Al}\end{array}$ & FCAY-4 & $7.0 \mathrm{dpa}, 320{ }^{\circ} \mathrm{C}$ & $v$ & $\checkmark$ & $v$ & $v$ & $v$ & o & $v$ & $v$ & $v$ & o & $\sigma$ & o \\
\hline $\begin{array}{c}\text { Fe- } \\
18 \mathrm{Cr}- \\
2.9 \mathrm{Al} \\
\end{array}$ & FCAY-4 & $7.0 \mathrm{dpa}, 320^{\circ} \mathrm{C}$ & $\checkmark$ & $v$ & $v$ & $\checkmark$ & $v$ & o & $v$ & o & $\checkmark$ & o & $\checkmark$ & o \\
\hline APMT & FCAY-4 & $7.0 \mathrm{dpa}, 320^{\circ} \mathrm{C}$ & $v$ & $\checkmark$ & $\checkmark$ & $v$ & $\checkmark$ & o & $v$ & o & o & * & o & * \\
\hline K720 & FCAY-4 & $7.0 \mathrm{dpa}, 320^{\circ} \mathrm{C}$ & $\checkmark$ & $\checkmark$ & $\checkmark$ & $\checkmark$ & $\checkmark$ & o & $v$ & o & o & * & o & * \\
\hline $\begin{array}{c}\text { Fe- } \\
10 \mathrm{Cr}- \\
4.8 \mathrm{Al} \\
\end{array}$ & FCAY-5 & target: $18 \mathrm{dpa}, 320^{\circ} \mathrm{C}$ & $\checkmark$ & o & o & o & 0 & o & 0 & o & o & 0 & o & o \\
\hline $\begin{array}{c}\mathrm{Fe}- \\
12 \mathrm{Cr}- \\
4.4 \mathrm{Al}\end{array}$ & FCAY -5 & target: $18 \mathrm{dpa}, 320^{\circ} \mathrm{C}$ & $\sim$ & o & 0 & o & o & o & 0 & o & o & o & o & o \\
\hline $\begin{array}{c}\mathrm{Fe}- \\
15 \mathrm{Cr}- \\
3.9 \mathrm{Al} \\
\end{array}$ & FCAY-5 & target: $18 \mathrm{dpa}, 320^{\circ} \mathrm{C}$ & $\checkmark$ & o & 0 & o & o & o & 0 & o & o & 0 & 0 & o \\
\hline $\begin{array}{c}\mathrm{Fe}- \\
18 \mathrm{Cr}- \\
2.9 \mathrm{Al} \\
\end{array}$ & FCAY-5 & target: $18 \mathrm{dpa}, 320^{\circ} \mathrm{C}$ & 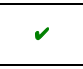 & o & 0 & o & o & o & 0 & o & 0 & o & o & o \\
\hline APMT & FCAY-5 & target: $18 \mathrm{dpa}, 320^{\circ} \mathrm{C}$ & $\checkmark$ & o & 0 & o & o & 0 & o & o & o & o & o & o \\
\hline K720 & FCAY-5 & target: $18 \mathrm{dpa}, 320^{\circ} \mathrm{C}$ & $\checkmark$ & o & o & $\mathbf{o}$ & o & o & o & 0 & o & o & o & o \\
\hline
\end{tabular}




\subsubsection{Passive SiC Thermometry}

All irradiation targets were designed for an irradiation temperature of $320^{\circ} \mathrm{C}$ based on the position within the HFIR. The non-instrumented capsules did not allow for real-time monitoring of the irradiation temperature. Analysis of the passive $\mathrm{SiC}$ thermometry was used to validate the target irradiation temperature. Dilatometric analysis of the passive $\mathrm{SiC}$ thermometry was conducted up to $600^{\circ} \mathrm{C}$ at a constant ramp rate of $1{ }^{\circ} \mathrm{C} / \mathrm{min}$ using a Netzsch $402 \mathrm{CD}$ dilatometer. Cooling was completed at a rate of $2.5^{\circ} \mathrm{C} / \mathrm{min}$. The temperature derivatives of the corrected expansion values outputted by the Netzsch 402 $\mathrm{CD}$ dilatometer was used to determine the instantaneous coefficient of thermal expansion $(\alpha)$. The $\alpha$ values from the heating and cooling curves were used to determine the indicated irradiation temperatures using the algorithm proposed by Campbell et al. [16]. The software used to execute the algorithm was obtained from the primary author allowing for consistent data analysis across multiple irradiation programs. An example of an outputted graph from the software is provided in Figure 4.

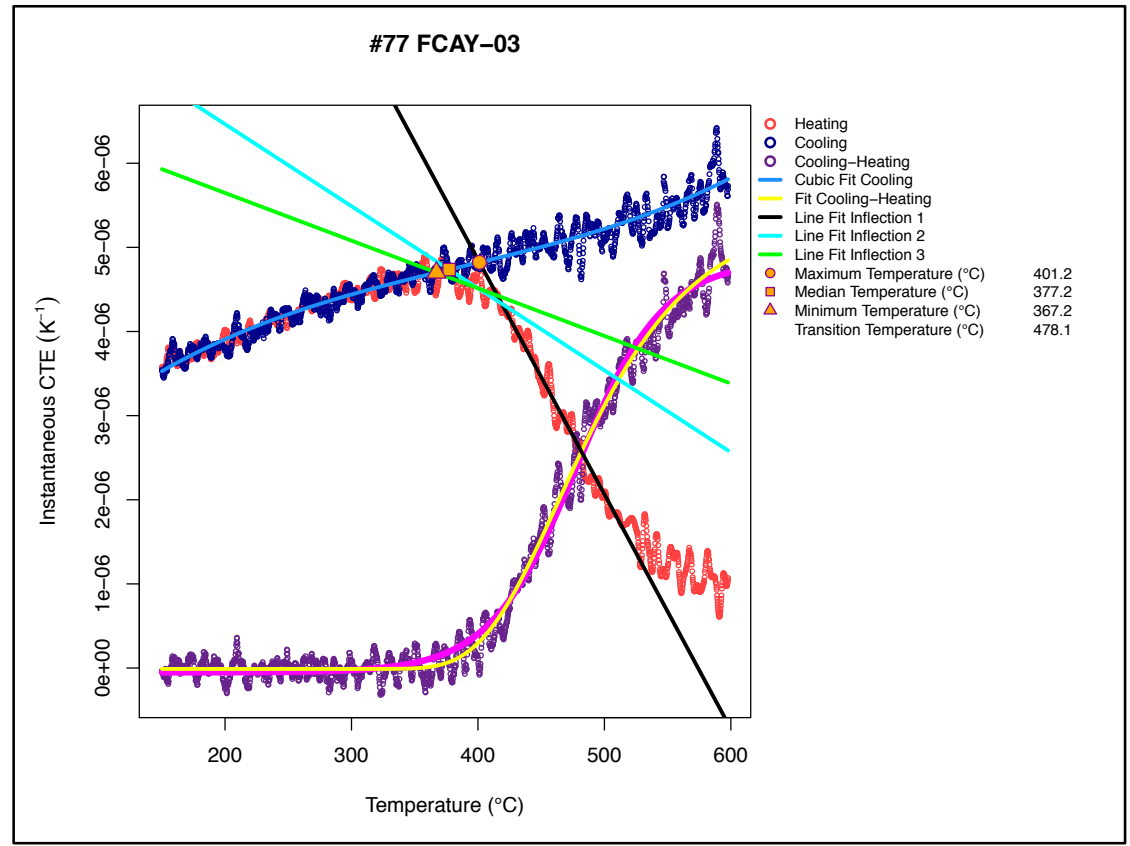

\section{Figure 4: Coefficient of thermal expansion as a function of temperature for a passive $\mathrm{SiC}$ thermometry sample for the FCAY3 irradiation target and software analysis output.}

Based on this analysis, the temperatures for each irradiation target were determined. For the FCAY1-3 capsules, 3 samples were run and analyzed at random and then averaged to determine the irradiation temperature. For the FCAY4 target, two SiC thermometry samples from the top, middle, and bottom of the target was analyzed to determine the overall axial temperature gradient in the irradiation target. A summary of the results of this analysis is provided in Table 4. As can be seen in Table 4, the FCAY1, 2, and 4 reached nominal irradiation temperatures close to the target temperature of $320^{\circ} \mathrm{C}$. For the FCAY 4 target, which was examined for axial temperature gradients, only a $10-20^{\circ} \mathrm{C}$ change in the analyzed temperature was noted throughout the target suggesting a relatively uniform irradiation temperature for the irradiation targets. The FCAY3 target showed a significantly higher nominal irradiation temperature $\left(381.9^{\circ} \mathrm{C}\right)$ versus the target temperature. This is most likely due to the THT-2 target position in HFIR having the highest neutron flux, Table 2, compared to the other target positions resulting in slightly elevated sample heating compared to the other positions. Never the less, the temperatures shown in Table 4 indicate all irradiation temperatures were maintained between the level of $300-400^{\circ} \mathrm{C}$, the key temperature window expected for LWR cladding applications. 
Table 4: Results of passive $\mathrm{SiC}$ thermometry analysis.

\begin{tabular}{ccccccc}
\hline Capsule ID & $\begin{array}{c}\text { HFIR } \\
\text { Position }\end{array}$ & $\begin{array}{c}\text { Dose } \\
\text { Rate } \\
(\mathbf{d p a} / \mathbf{s})\end{array}$ & $\begin{array}{c}\text { Dose } \\
\mathbf{( d p a )}\end{array}$ & $\begin{array}{c}\text { Min. Irradiation } \\
\text { Temp. }\left({ }^{\circ} \mathbf{C}\right)\end{array}$ & $\begin{array}{c}\text { Nominal } \\
\text { Irradiation } \\
\text { Temp. }\left({ }^{\circ} \mathbf{C}\right)\end{array}$ & $\begin{array}{c}\text { Max. } \\
\text { Irradiation } \\
\text { Temp. }\left({ }^{\circ} \mathbf{C}\right)\end{array}$ \\
\hline \hline FCAY1 & HT & $7.7 \times 10^{-7}$ & 0.3 & $293.8 \pm 24.8$ & $334.5 \pm 0.6$ & $360.2 \pm 4.2$ \\
FCAY2 & HT & $7.7 \times 10^{-7}$ & 0.8 & $330.2 \pm 11.4$ & $355.1 \pm 3.4$ & $377.8 \pm 4.7$ \\
FCAY3 & THT-2 & $8.1 \times 10^{-7}$ & 1.8 & $362.2 \pm 4.8$ & $381.9 \pm 5.4$ & $406.1 \pm 3.5$ \\
FCAY4 - top & PTP-7 & $7.9 \times 10^{-7}$ & 7.0 & $297.3 \pm 15.3$ & $309.4 \pm 14.0$ & $342.4 \pm 12.3$ \\
FCAY4 - middle & PTP-7 & $7.9 \times 10^{-7}$ & 7.0 & $316.1 \pm 13.6$ & $329.8 \pm 9.8$ & $361.5 \pm 5.2$ \\
FCAY4 - bottom & PTP-7 & $7.9 \times 10^{-7}$ & 7.0 & $303.6 \pm 12.5$ & $320.5 \pm 9.8$ & $352.1 \pm 7.0$ \\
FCAY5 & PTP-7 & TBD & TBD & TBD & TBD & TBD \\
\hline
\end{tabular}

\subsubsection{Mechanical Testing}

All mechanical tests conducted to date were uniaxial tensile tests and were conducted on the same test frame housed within ORNL's IMET facility to enable consistency across the testing database. Both unirradiated and irradiated samples were tested on the same tensile frame. All testing was conducted using shoulder loading at a crosshead speed of $0.0055 \mathrm{~mm} / \mathrm{s}$ corresponding to a strain rate of $\sim 10^{-3} \mathrm{~s}^{-1}$ on a screw-driven machine. The engineering strain was calculated from the recorded crosshead separation using the initial gauge length of $5.0 \mathrm{~mm}$. The thickness and width of the gage region from each specimen was measured prior to testing. The engineering stress was calculated by dividing the applied load by the initial cross-sectional area. All tensile tests were performed at room temperature. One tensile test was performed for each sample and condition as archival samples are to be used for high temperature tensile testing once the capability is restored within the IMET facility.

\subsubsection{Small Angle Neutron Scattering}

SANS was performed at ORNL on the CG-2 general-purpose beam line (GP-SANS) at the HFIR [17]. Generally, SANS was completed on the fracture tensile heads after mechanical testing. For samples from the FCAY4 irradiation target, samples for SANS were cut from non-tested tensile heads to reduce the sample activity therefore enabling SANS to be conducted on these samples. Samples for SANS were wrapped in Al foil to prohibit the spread of removable containment and reduce sample handling logistics. $\mathrm{Al}$ foil packets housing samples were mounted over $2 \mathrm{~mm}$ diameter apertures on a cadmium plate mounted on the standard sample exchanger of the GP-SANS beam line using adhesive wax.

The data were measured at three detector settings - sample to detector distances of $1.079 \mathrm{~m}$ and $7.779 \mathrm{~m}$ using $0.472 \mathrm{~nm}$ neutrons and of $19.279 \mathrm{~m}$ using $1.2 \mathrm{~nm}$ neutrons - with the detector laterally offset by 0.4 $\mathrm{m}$ to maximize the accessible range of momentum transfer, $\mathrm{Q}$, in each setting. The three settings together spanned the range $0.01<\mathrm{Q}<10 \mathrm{~nm}^{-1}$. An example of the raw data from an Alkrothal 720 specimen irradiated to $0.3 \mathrm{dpa}$ at $335^{\circ} \mathrm{C}$ is shown in Figure 5 . 

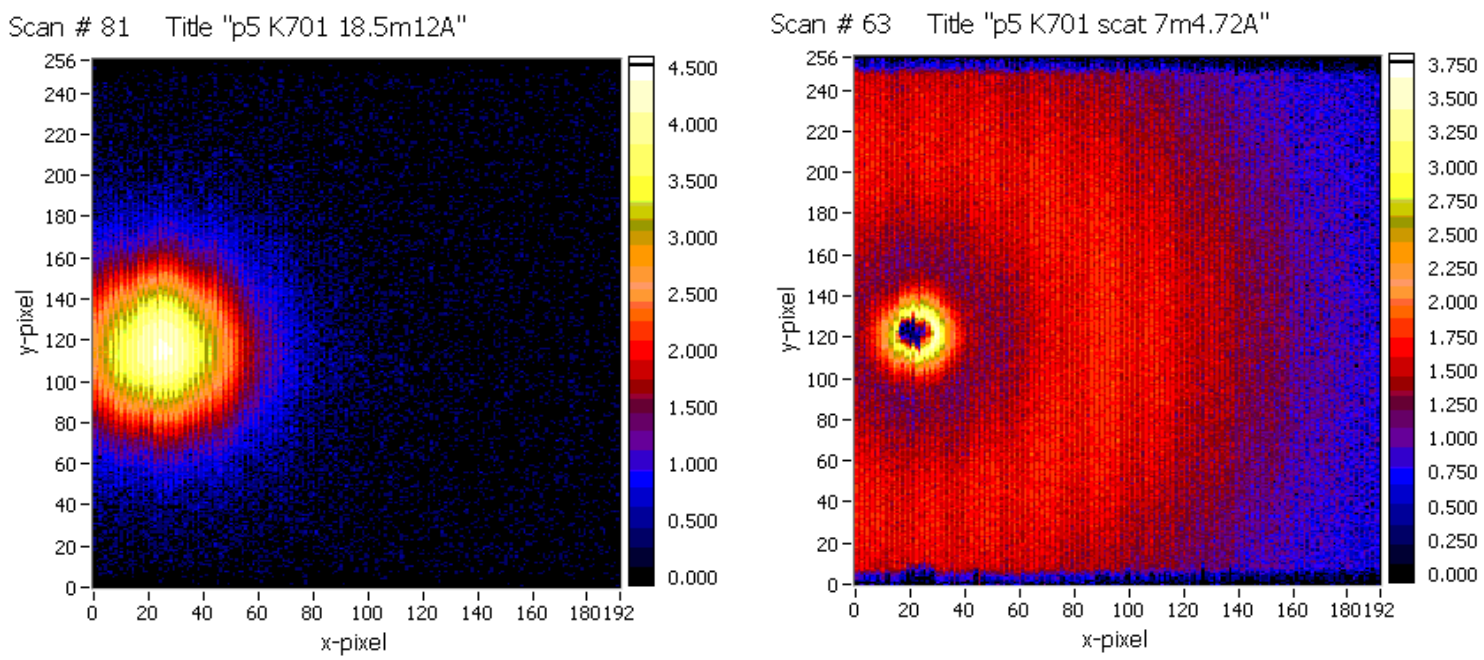

Figure 5: Example of raw data collected on the GP-SANS line at ORNL for two detector settings for the Alkrothal 720 specimen irradiated to 0.3 dpa at $335^{\circ} \mathrm{C}$.

The data were placed on the $\mathrm{cm}^{-1}$ absolute scale by normalizing the medium data to the attenuated direct beam after correction for thickness and transmission. Data in the other two settings were scaled to match the medium data to generate the combined curves. All measurements were performed at room temperature. Measurements were performed on a single end of each fractured tensile specimen with a nominal thickness of $0.5 \mathrm{~mm}$. Multiple scattering corrections were negligible. An example of the reduced data based on the raw data collected is shown in Figure 6. Fitting was completed using the Igor-Pro based data package developed at ORNL. The models used for nonlinear least-squares fitting assumed spheres interacting with an exclusion volume due to either a uniformly-depleted region around the precipitates or a minimum distance of approach between them; an example of the fitting parameters and wellness of fit are provided in Figure 6.

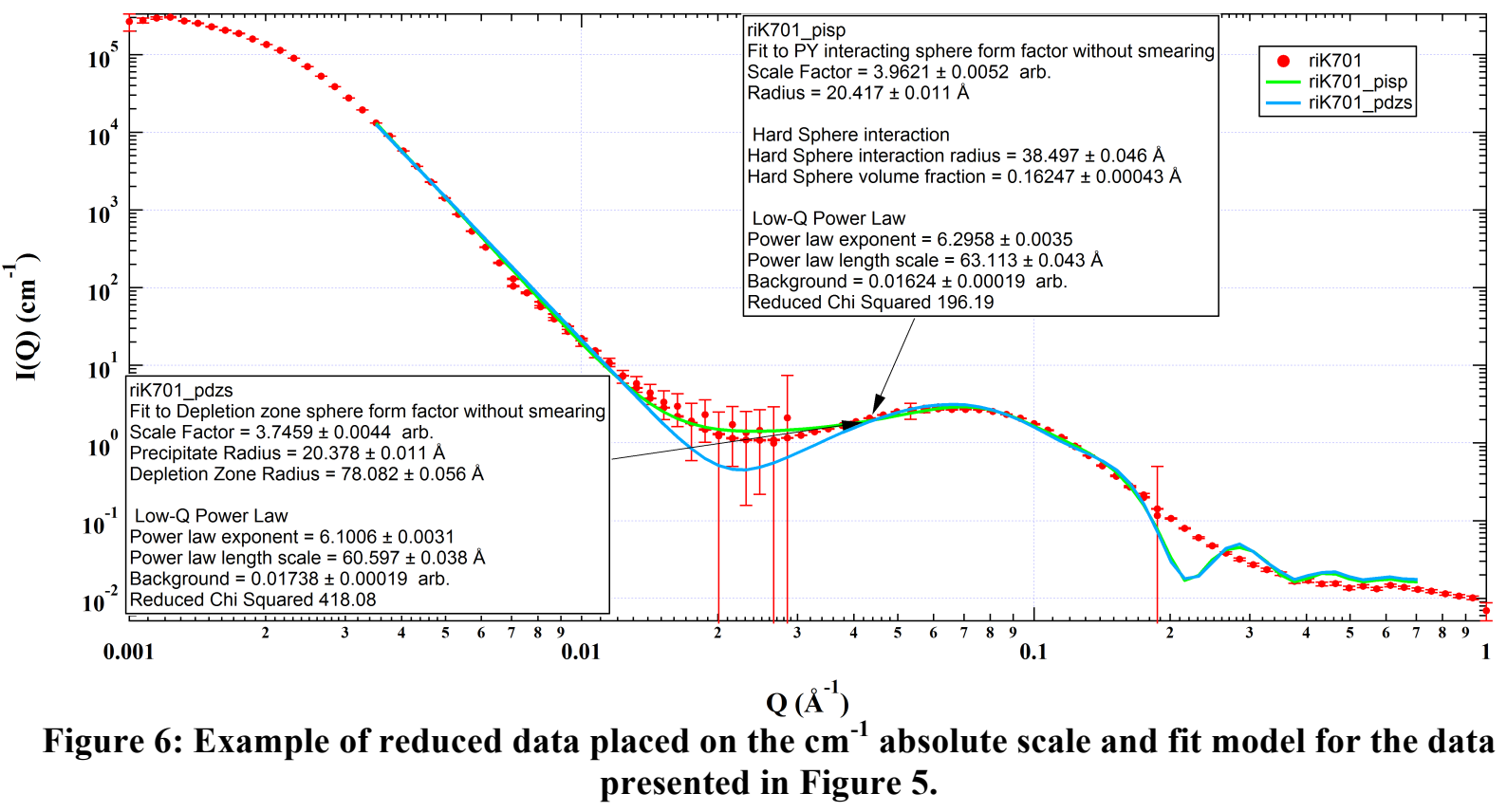

As a magnet was not applied during analysis to remove composition ambiguity in the measurement, a parametric analysis based on the composition of the clusters has been completed but will not be 
presented. To remain consistent with literature, within this report it assumed the Cr-rich regions have a composition of Fe-82.2-3.45 Al (at.\%). Regardless of the composition ambiguity in the analysis, the accuracy of the absolute scaling calibration procedure of SANS data is typically assumed to be nominally $10 \%$. However, this uncertainty applies to the universal scaling factor used for all of the data and will thus change the scale of the data for the volume fraction without affecting the relative changes in value. There is a similar, but more difficult to estimate, uncertainty in the scaling associated with the nuclear scattering length density of the $\alpha^{\prime}$ phase relative to the matrix. The uncertainty in the individual precipitate particle volume from modeling - the largest contributing factor to the relative uncertainty between quantitative data points-is determined from the fitting uncertainties to average less than $5 \%$ per sample. Here, it is assumed the uncertainty in the overall scale in the volume fraction data presented is approximately $20 \%$, while the relative uncertainty between each composition relative to the others is $\leq 5 \%$.

\subsubsection{Sample cleaning and preparation for microscopy}

Samples for microscopy were received within ORNL's LAMDA facility after mechanical testing and/or SANS analysis. To reduce removable contamination and clean the surfaces prior to focused ion beam (FIB) sample preparation, a procedure was put in place where samples were cleaned in methanol in an ultrasonic bath for approximately 5 minutes. Activities of samples were measured after cleaning and then cleaning was repeated until no measurable changes in activity were observed between re-cleaning steps. Final activities were then reported to enable sample exchanges within the LAMDA facility. Following cleaning, samples were prepared using standard metallography techniques to remove any surface oxidation or interaction layer that might have formed during irradiation. This also ensured that the investigated samples were free from surface defects and damage incurred during sample machining. After metallographic preparation to a near mirror finish, samples were mounted to scanning electron microscopy (SEM) stubs to enable FIB preparation techniques.

\subsubsection{Focused ion beam techniques}

Samples were prepared for S/TEM and APT using either a FEI Quanta 3D FEG housed at the Center for Advanced Energy Studies (CAES) or either the FEI Quanta 3D 200i or FEI Versa 3D FEG housed at ORNL's LAMDA facility. FIB preparation was used in lieu of electropolishing to reduce the magnetic aberrations observed during specimen tilting in S/TEM and to reduce sample activity resulting in the elimination of high signal to background ratios during APT or STEM-EDS investigations. Standard FIB preparation techniques were employed to fabricate specimens for both techniques (APT or S/TEM). Care was taken to reduce FIB-induced damage that could create artifacts during microscopy investigations. All samples were thinned to either electron transparency for S/TEM or critical radius size for APT and then cleaned with a $5 \mathrm{kV}$ Ga ion beam and finished with a $2 \mathrm{kV}$ Ga ion beam regardless of FIB used. At least two daughter samples were fabricated per alloy and irradiation condition investigated for both techniques. Figure 7 shows scanning electron microscopy (SEM) images of completed samples ready for investigation. 
a)

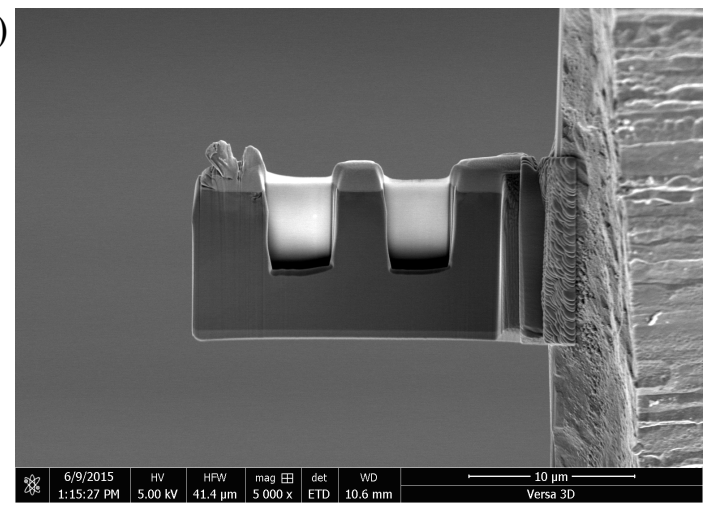

b)

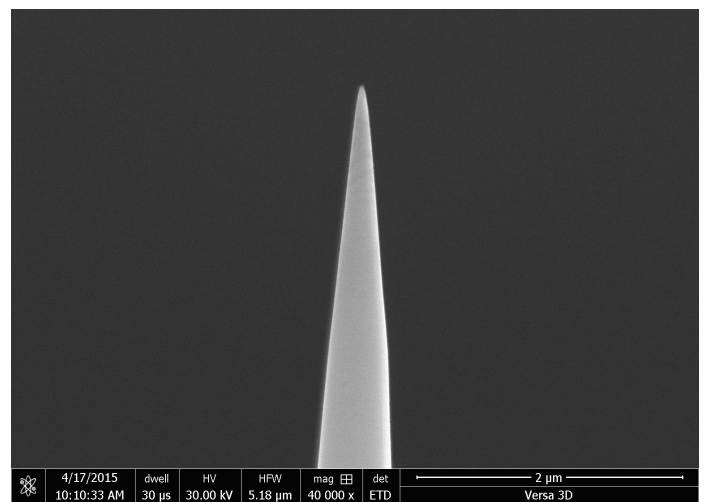

Figure 7: SEM micrograph of prepared samples using FIB preparation techniques, a) a S/TEM electron transparent foil and b) a APT sharpened tip.

\subsubsection{Transmission and Scanning Transmission Electron Microscopy}

A Philips CM200 FEG-S/TEM operating at $200 \mathrm{kV}$, a JEOL JEM-2100F FEG-S/TEM operating at 200 $\mathrm{kV}$, or a FEI Talos F200X operating at $200 \mathrm{kV}$ housed at ORNL was used for S/TEM investigations. The dislocation loop type (i.e., dislocation loops with Burgers vector of either $a / 2\langle 111\rangle$ or $a\langle 100\rangle$ ) was determined by the observed morphologies during annular bright-field (ABF) STEM imaging on the [100] zone axis. Details on the conditions and principles of dislocation imaging in STEM mode can be found in Parish et al. [18]. Foil thickness was determined using convergent beam electron diffraction (CBED) analysis [19]. The defect densities were determined from the plots of slope of areal density versus foil thickness to correct for near-surface FIB-induced artifacts and/or loss of glissile defects to the foil surface [20-22]. Electron dispersive spectroscopy (EDS) was conducted on the FEI Talos F200X as this system is outfitted with a 0.9 srad solid angle of collection for X-rays and a proprietary high brightness source allowing an ultra-high X-ray spectrum imaging efficiency over other STEM-EDS systems currently qualified for radiological use. Scan sizes for STEM-EDS spectrum imaging varied, but all analysis was conducted at $450 \mathrm{kX}$ indicated magnification using a probe current greater than $1 \mathrm{nA}$ and acquisition times between 15-30 minutes per scan.

\subsubsection{Atom Probe Tomography}

The Cameca LEAP 4000 HR atom probes housed at both the Center for Nanophase Materials Sciences (CNMS) at ORNL and at CAES were employed to collect data on FIB-prepared APT specimens. The local electrode atom probes (LEAP) were operated in the laser mode at a base specimen temperature of $50 \mathrm{~K}$, pulse repetition rate of $200 \mathrm{kHz}$, and a laser energy of $50 \mathrm{pJ}$. The detection rate was typically set at $0.5 \%$. Data sets with at least 10 million ions were collected from a minimum of two tips from each condition.

The atom probe data was reconstructed and analyzed using the Cameca Visualization and Analysis Software (IVAS 3.6.8). Standard values were used for the image compression factor (1.6-1.7), the average evaporation field (33 V nm-1), and the detector efficiency (0.36) were used in the reconstruction. Cr-rich $\alpha^{\prime}$ clusters were analyzed using the maximum-separation distance cluster-finding algorithm packaged within the IVAS software. The two primary inputs to this algorithm are the maximum separation distance, $\mathrm{d}_{\max }$, defining whether $\mathrm{Cr}$ atoms belong to the same cluster, and minimum cluster size, $\mathrm{N}_{\min }$, defining the smallest number of atoms that can define a statistically significant cluster. Careful selection of these parameters is essential for an accurate analysis as improper values will result in either inclusion of artificially generated clusters or omission of statistically significant clusters. Once the algorithm has 
identified clusters, their sizes and compositions can be analyzed and the number density and volume fraction of clusters in the irradiated matrix can be determined.

\section{RESULTS}

\subsection{Mechanical Testing}

The resulting room-temperature engineering stress-strain curves before and after irradiation are shown in Figure 8. From the tensile curves in Figure 8, the values for the yield strength $\left(\sigma_{y}\right)$, change in yield stress $\left(\Delta \sigma_{y}\right)$, ultimate tensile strength (UTS), uniform elongation (UE), and total elongation (TE) were calculated and provided in Table 5. For the Generation I FeCrAl alloys, significant radiation hardening was observed, even at low doses especially for the high $\mathrm{Cr}$ content alloys. The highest hardening was observed in the $7.0 \mathrm{dpa}, 320^{\circ} \mathrm{C}$ irradiated samples. The $1.8 \mathrm{dpa}, 382^{\circ} \mathrm{C}$ samples showed a peculiarity where lower hardening values were observed than at lower doses, an effect most likely due to the $\sim 50^{\circ} \mathrm{C}$ higher irradiation temperature resulting in a significant recovery of prior cold work. Such effect is not observed in the non-cold worked Alkrothal 720 sample where a consistent trend was observed of increasing change in yield strength with increasing radiation dose. The Alkrothal 720 sample irradiated to $7.0 \mathrm{dpa}, 320^{\circ} \mathrm{C}$ showed the highest radiation-induced hardening of any sample investigated to date. A clear effect on composition is observed, where radiation-induced hardening increased with increasing $\mathrm{Cr}$ content in the irradiated model FeCrAl alloys. The APMT alloy showed brittle fracture when conducting room temperature tensile tests when irradiated above $0.3 \mathrm{dpa}$. This result could be due to the heat of APMT used for this study being an early heat with non-optimized properties for room temperature applications. Further investigations are underway to determine the mechanism(s) behind the brittle fracture in this alloy at elevated irradiation doses.
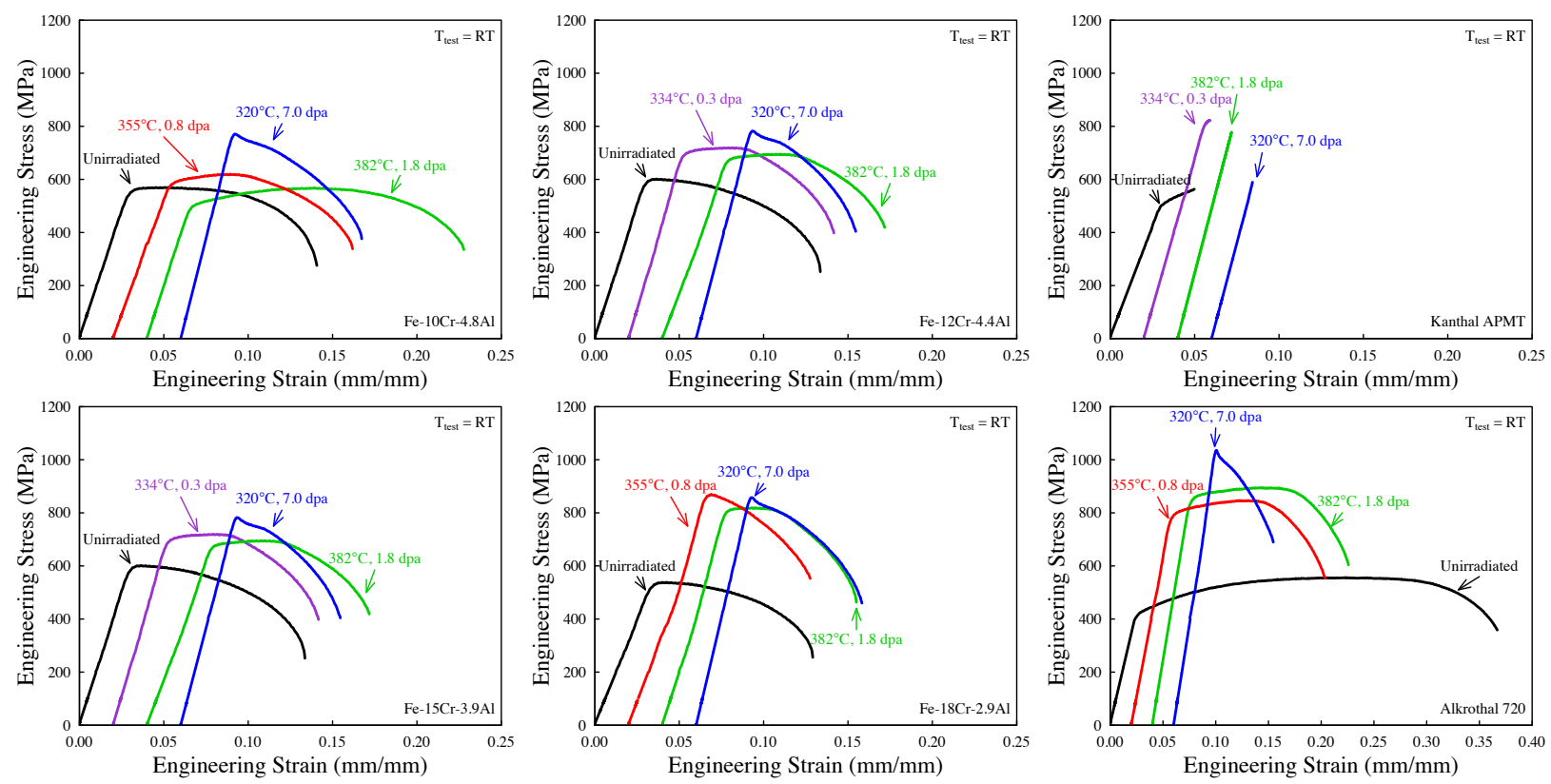

Figure 8: Engineering stress-strain curves for all alloys before irradiation (black lines) and after irradiation (colored lines).

As seen in Table 5, typically radiation-induced hardening (increase in $\Delta \sigma_{y}$ ) corresponded with a decrease in both the uniform and total elongation of the samples. Irradiation at $7 \mathrm{dpa}, 320^{\circ} \mathrm{C}$ in the model alloys resulted in an almost complete loss of uniform elongation with values near $0.1-0.2 \%$ while the total 
elongation values seem to saturate near $7-10 \%$. Such observation indicates a lower effect of composition on the ductility parameters in the alloys compared to the hardening values. Lower doses, especially the higher temperature $1.8 \mathrm{dpa}, 382^{\circ} \mathrm{C}$ samples showed higher elongation values indicating higher irradiation temperatures could enable better retention of the ductility in the samples. The commercial Alkrothal 720 alloy showed similar behavior to the model alloys but a larger loss in the ductility parameters for the same irradiation conditions. To date, no SEM-based fractography has been completed to determine the fracture modes in the samples or determine the reduction in area during tensile testing.

Table 5: Summary of mechanical properties of unirradiated and irradiated specimens.

\begin{tabular}{|c|c|c|c|c|c|c|c|}
\hline \multirow[b]{2}{*}{ Alloy } & \multirow{2}{*}{$\begin{array}{l}\text { Irr. Dose } \\
\quad \text { (dpa) }\end{array}$} & \multirow{2}{*}{$\begin{array}{l}\text { Irr. Temp } \\
\quad\left({ }^{\circ} \mathrm{C}\right)\end{array}$} & \multicolumn{5}{|c|}{ Properties at $24^{\circ} \mathrm{C}$} \\
\hline & & & $\begin{array}{c}\sigma_{\mathrm{y}} \\
(\mathbf{M P a})\end{array}$ & $\begin{array}{c}\text { UTS } \\
\text { (MPa) }\end{array}$ & $\begin{array}{c}\mathrm{UE} \\
(\mathbf{m m} / \mathbf{m m})\end{array}$ & $\begin{array}{c}\text { TE } \\
(\mathbf{m m} / \mathbf{m m})\end{array}$ & $\begin{array}{r}\Delta \sigma_{\mathrm{y}} \\
\mathbf{M P a}\end{array}$ \\
\hline \multirow{4}{*}{$\begin{array}{c}\text { Fe-10Cr- } \\
4.8 \mathrm{Al}\end{array}$} & \multicolumn{2}{|c|}{ As-received } & 540 & 570 & 0.023 & 0.126 & - \\
\hline & 0.8 & 355 & 530 & 620 & 0.034 & 0.123 & -10 \\
\hline & 1.8 & 382 & 465 & 568 & 0.07 & 0.171 & -75 \\
\hline & 7 & 320 & 755 & 771 & 0.001 & 0.092 & 215 \\
\hline \multirow{4}{*}{$\begin{array}{c}\text { Fe-12Cr- } \\
4.4 \mathrm{Al}\end{array}$} & \multicolumn{2}{|c|}{ As-received } & 576 & 602 & 0.006 & 0.121 & - \\
\hline & 0.3 & 334 & 676 & 696 & 0.028 & 0.107 & 100 \\
\hline & 1.8 & 382 & 667 & 719 & 0.027 & 0.103 & 91 \\
\hline & 7 & 320 & 775 & 783 & 0.001 & 0.092 & 199 \\
\hline \multirow{4}{*}{$\begin{array}{c}\text { Fe-15Cr- } \\
\text { 3.9Al }\end{array}$} & \multicolumn{2}{|c|}{ As-received } & 566 & 612 & 0.005 & 0.104 & - \\
\hline & 0.3 & 334 & 813 & 817 & 0 & 0.083 & 247 \\
\hline & 1.8 & 382 & 766 & 793 & 0.034 & 0.135 & 200 \\
\hline & 7 & 320 & 823 & 843 & 0.002 & 0.074 & 257 \\
\hline \multirow{4}{*}{$\begin{array}{c}\text { Fe-18Cr- } \\
2.9 \mathrm{Al}\end{array}$} & \multicolumn{2}{|c|}{ As-received } & 519 & 539 & 0.008 & 0.113 & - \\
\hline & 0.8 & 355 & 801 & 870 & 0 & 0.075 & 282 \\
\hline & 1.8 & 382 & 813 & 819 & 0.011 & 0.091 & 294 \\
\hline & 7 & 320 & 842 & 857 & 0.001 & 0.081 & 323 \\
\hline \multirow{4}{*}{$\begin{array}{c}\text { Alkrothal } \\
720\end{array}$} & \multicolumn{2}{|c|}{ As-received } & 403 & 557 & 0.191 & 0.346 & - \\
\hline & 0.8 & 355 & 810 & 895 & 0.068 & 0.161 & 407 \\
\hline & 1.8 & 382 & 768 & 847 & 0.062 & 0.157 & 365 \\
\hline & 7 & 320 & 1033 & 1035 & 0 & 0.067 & 630 \\
\hline \multirow{4}{*}{ APMT } & \multicolumn{2}{|c|}{ As-received } & 502 & 563 & 0.016 & 0.016 & - \\
\hline & 0.3 & 334 & 810 & 823 & 0.002 & 0.002 & 308 \\
\hline & 1.8 & 382 & 778 & 778 & 0 & 0 & 276 \\
\hline & 7 & 320 & 590 & 590 & 0 & 0 & 88 \\
\hline
\end{tabular}

yield strength $\left(\sigma_{y}\right)$, change in yield stress $\left(\Delta \sigma_{y}\right)$, ultimate tensile strength (UTS), uniform elongation (UE), and total elongation (TE) 


\subsection{Scanning/Transmission Electron Microscopy}

\subsubsection{Dislocation and dislocation loop morphologies}

As indicated in Table 3, select samples have been investigated to determine the dislocation and dislocation loop morphologies in the unirradiated and irradiated alloys. A majority of the information regarding this analysis has been reported previously [11]. Here, a brief summary of the previously reported results is provided as well as new analysis conducted after the initial reporting.

All samples investigated in the irradiated state have shown a high number density of dislocation loops with a varying degree of dislocation line networks. Qualitatively, the low dose model alloys which had prior cold-work tended to show higher degrees of dislocation line networks compared to higher dose model alloys. The Alkorthal 720 sample showed almost no dislocation networking in either the unirradiated or irradiated state indicting no cold working was applied to these samples prior to irradiation.

Dislocation loop Burgers vector, and hence type, were determined by imaging the samples on the [100] zone axis in STEM mode. This configuration, as described by Parish et al. [18], enables all g-vectors on the [100] zone axis to be excited simultaneously therefore allowing imaging dislocation loops with Burgers vector of $a / 2\langle 111\rangle$ or $a\langle 100\rangle$. The Burgers vector of each loop was determined based on the dislocation-loop maps provided by Yao et al. [23] and comparing them to the morphologies observed in the STEM images, i.e. edge-on loops, near perfect circles, or ellipses. To date, no determination of whether loops were either vacancy or interstitial type has been conducted. To get quantitative number densities for different loop types, a plot of areal density versus specimen thickness was generated on a per sample and irradiation condition basis, as stated earlier. It should be noted that the areal density versus thickness plots for the $a / 2\langle 111\rangle$ dislocation loops, which was used for density quantification, did not intercept at zero. This indicates that a population of the $a / 2\langle 111\rangle$ loops in all samples were lost to the foil surface sometime before STEM analysis, an artifact which is unavoidable for this technique.

For all samples investigated (including both Generation I FeCrAl alloys and commercial alloys), both $a / 2\langle 111\rangle$ and $a\langle 100\rangle$ dislocation loops were observed in the samples although the size and number density for both loop types varied based on irradiation condition and alloy investigated. The observation of both loop types across both the model and commercial alloys indicates that the minor solute additions in the commercial alloys did not suppress the type of dislocation loops formed under irradiation, although minor solute additions could have an effect on their size and number density.

All investigated samples also included a population of black dot damage. For those samples exhibiting outlier number densities of black dots, the data was removed from analysis. This is due to black dot formation known to be a possible artifact produced during high-energy FIB sample preparation [24]. Generally, black dots had a size less than $10 \mathrm{~nm}$ in all investigated alloys. This result is expected because as the dislocation loop size is reduced, the contrast of the non-edge on loops begins to collapse/coalesce making it difficult to uniquely distinguish the dislocation loop morphology (i.e. edge-on or open loop). When quantitative measurements were made of the black dot population, the relative size and number densities remained unchanged between alloy and irradiation condition indicating the black dots are most likely either $a / 2\langle 111\rangle$ or $a\langle 100\rangle$ dislocation loops that can not be uniquely identified when their sizes are sufficiently small.

The highest degree of analysis has been completed on the $1.8 \mathrm{dpa}, 382^{\circ} \mathrm{C}$ irradiated Generation I FeCrAl alloys. The size and number density of all observed dislocation microstructures are reproduced in Table 6 from Field et al. [11]. To summarize, no apparent tends in the $a / 2\langle 111\rangle$ dislocation loop density was observed based on model alloy composition. The number density of $a / 2\langle 111\rangle$ dislocation loops was significantly higher in the $\mathrm{Fe}-12 \mathrm{Cr}-4.4 \mathrm{Al}$ specimen and lowest in the $\mathrm{Fe}-10 \mathrm{Cr}-4.8 \mathrm{Al}$, and the average size 
was between 19.8 and $31.9 \mathrm{~nm}$. For the $a\langle 100\rangle$ dislocation loops, the lowest number density was in the Fe-10Cr-4.8Al alloy while all other model alloys had similar number densities that hover around $\sim 2 \times 10^{20}$ $\mathrm{m}^{-3}$. Number density played a role on the size for the $a\langle 100\rangle$ dislocation loops as the largest observed loop diameters were in the Fe-10Cr-4.8Al alloy. The ratio of $a\langle 100\rangle$ dislocation loops to $a / 2\langle 111\rangle$ dislocation loops varied based on alloy composition with the $\mathrm{Fe}-18 \mathrm{Cr}-2.9 \mathrm{Al}$ alloy having a ratio near three to four while all other alloys were nearly double. For the model alloys, no evidence of grain boundaries influencing the dislocation microstructure was observed.

Table 6: Summary of average size and number density of STEM-identified defects in Generation I FeCrAl specimens irradiated in the HFIR reactor at $1.8 \mathrm{dpa}, 382^{\circ} \mathrm{C}$. Reproduced from [11].

\begin{tabular}{lcccc}
\hline \multirow{2}{*}{ Property } & \multicolumn{4}{c}{ Alloy } \\
\cline { 2 - 5 } & Fe-10Cr-4.8Al & Fe-12Cr-4.4Al & Fe-15Cr-3.9Al & Fe-18Cr-2.9Al \\
\hline \hline Cr content (wt \%) & 10.01 & 11.96 & 15.03 & 17.51 \\
$\boldsymbol{\rho}_{\text {unirr }}\left(\mathbf{m}^{-\mathbf{2}}\right)$ & $6.3 \pm 1.0 \times 10^{13}$ & $1.5 \pm 0.7 \times 10^{14}$ & $1.5 \pm 0.6 \times 10^{14}$ & $1.0 \pm 0.5 \times 10^{14}$ \\
$\boldsymbol{\rho}_{\text {irr }}\left(\mathbf{m}^{-\mathbf{2}}\right)$ & $2.7 \pm 0.9 \times 10^{13}$ & $4.7 \pm 1.3 \times 10^{13}$ & $2.9 \pm 1.2 \times 10^{13}$ & $6.0 \pm 0.9 \times 10^{13}$ \\
$\mathbf{d}_{\mathbf{a}<\mathbf{1 0 0}>}(\mathbf{n m})$ & $52.5 \pm 23.8$ & $29.7 \pm 13.7$ & $41.1 \pm 24.8$ & $32.0 \pm 15.6$ \\
$\boldsymbol{\rho}_{\mathrm{a}<\mathbf{1 0 0}>}\left(\mathbf{m}^{-\mathbf{3}}\right)$ & $3.4 \pm 0.5 \times 10^{19}$ & $2.3 \pm 0.2 \times 10^{20}$ & $1.0 \pm 0.6 \times \times 10^{20}$ & $2.0 \pm 0.3 \times 10^{20}$ \\
$\mathbf{d}_{\mathrm{a} / 2<\mathbf{1 1 1}>}\left(\mathbf{n m}_{\mathbf{n}}\right)$ & $31.9 \pm 18.7$ & $19.8 \pm 11.7$ & $30.4 \pm 16.8$ & $25.5 \pm 15.4$ \\
$\boldsymbol{\rho}_{\mathrm{a} / 2<\mathbf{1 1 1}>}\left(\mathbf{m}^{-3}\right)$ & $2.6 \pm 0.6 \times 10^{20}$ & $1.5 \pm 0.3 \times 10^{21}$ & $7.9 \pm 1.2 \times 10^{20}$ & $7.2 \pm 1.0 \times 10^{20}$ \\
$\mathbf{d}_{\mathbf{b d}}(\mathbf{n m})$ & $9.1 \pm 3.2$ & $8.2 \pm 4.3$ & $9.8 \pm 3.8$ & $8.4 \pm 3.4$ \\
$\boldsymbol{\rho}_{\mathbf{b d}}\left(\mathbf{m}^{-\mathbf{3}}\right)$ & $1.0 \pm 0.1 \times 10^{20}$ & $1.6 \pm 0.1 \times 10^{21}$ & $3.2 \pm 1.2 \times 10^{20}$ & $8.8 \pm 1.1 \times 10^{20}$ \\
\hline
\end{tabular}

$\rho$, dislocation density; $d$, effective diameter

Subscripts: unirr, dislocation line density in unirradiated condition; irr, dislocation line density in irradiated condition; a $<100>$, a $\langle 100\rangle$

dislocation loops; $a / 2<111\rangle, a / 2\langle 111\rangle$ dislocation loops; bd, black dots

Such limited effect of the grain boundaries on the dislocation microstructure was not true for the Alkrothal 720 sample irradiated to $1.8 \mathrm{dpa}, 320^{\circ} \mathrm{C}$. This sample had clear differences in the dislocation loop size and number density near high angle grain boundaries, as shown in the STEM micrograph in Figure 9. For all random high angle grain boundaries (RHAGBs) observed in the irradiated Alkrothal 720 sample, dislocation loops were observed to have a denuded zone in the specimen directly adjacent to the grain boundaries followed by a peak zone directly adjacent to the denuded zone. The total defect number density was enhanced in the peak zone. With increasing distance from the grain boundary, the dislocation size and number density became asymptotic and normalized out to the morphologies observed in the grain interiors. Limited line dislocation networking was observed in any of these zones.

A specialized analysis procedure was developed to determine the quantitative dislocation loop size and type as a function of distance away from the grain boundary to quantify the grain boundary effect on the dislocation loop formation in this specimen. Currently, three RHAGBs have been quantified. An example of the identified loops based on the image provided in Figure 9 is provided in Figure 10. The exact position center for each loop was determined enabling the quantification of not only the distance of each loop to the grain boundary but also the distance of each defect from the remaining population. Based on this analysis, the denuded zone, peak zone, and grain interior size number densities for each loop type were determined. Also, the average minimum defect separation (MDS) distance was recorded. At the time of reporting, the specimen foil thickness had not been quantified using CBED analysis and therefore a uniform specimen thickness of $100 \mathrm{~nm}$ is assumed. Some error is intrinsic due to this current assumption, although future work will directly determine the specimen thickness therefore eliminating this error from the analysis. Table 7 summarizes the resulting quantification for the three RHAGBs. Future work seeks to characterize more grain boundaries and dislocation loop morphologies for this sample. 


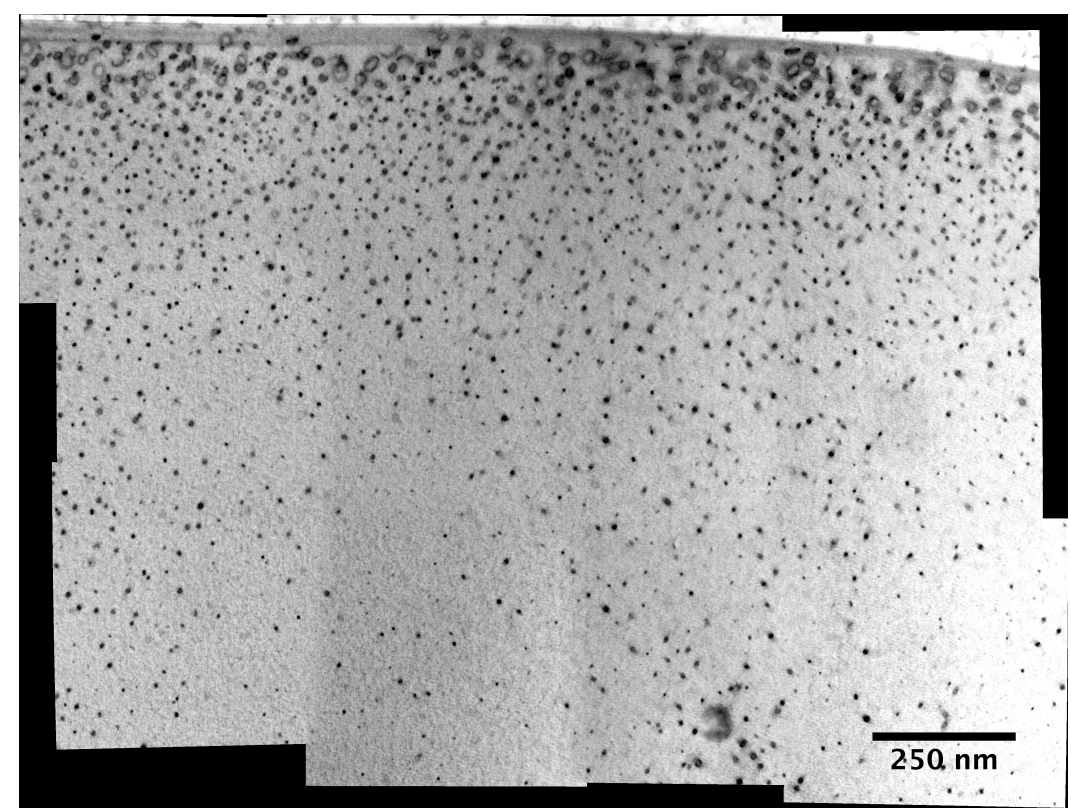

Figure 9: Stitched bright field STEM image showing dislocation loops near a random high angle grain boundary irradiated to $1.8 \mathrm{dpa}, 320^{\circ} \mathrm{C}$ in a Alkrothal 720 sample.

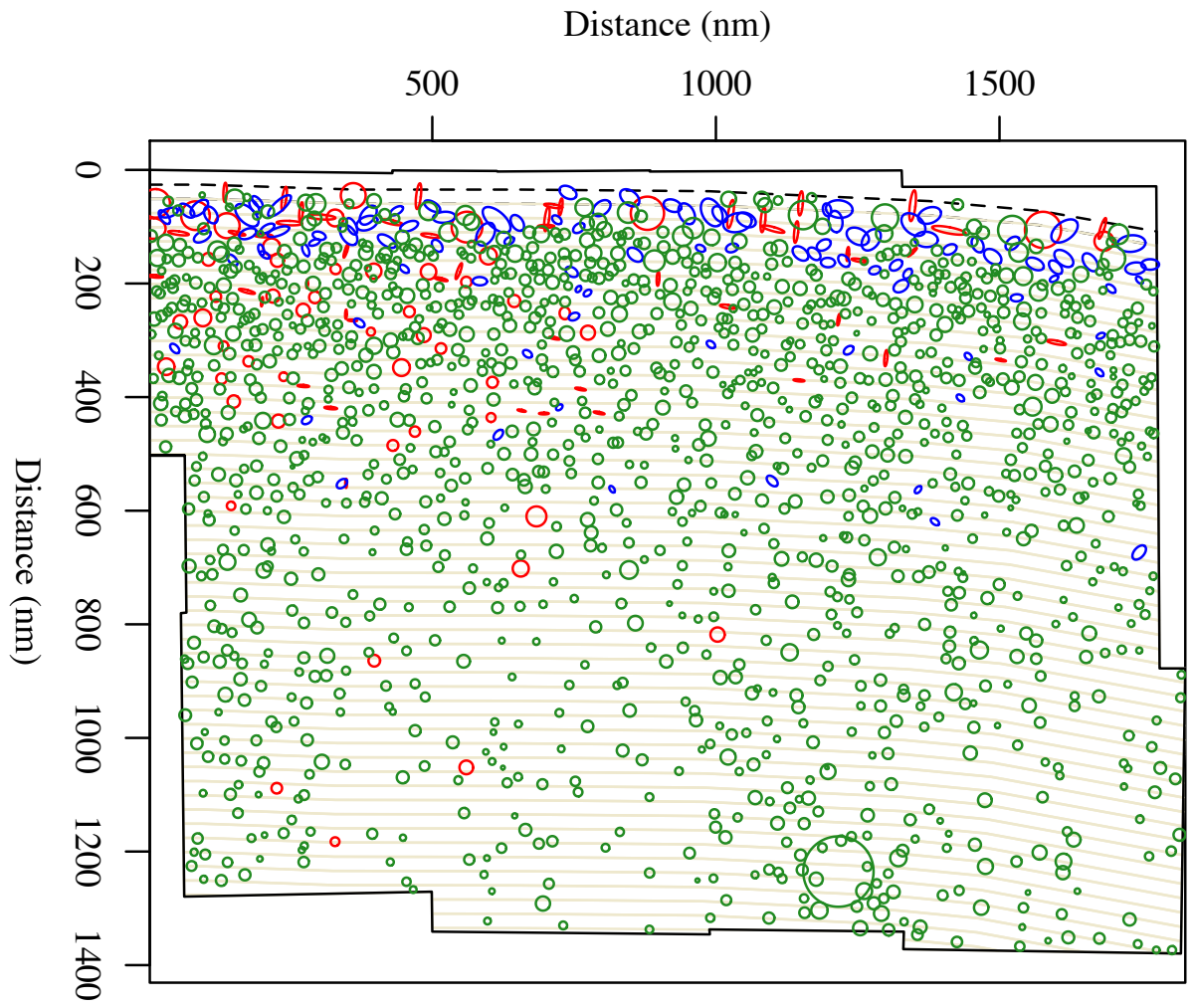

Figure 10: Outputted image based on specialized data analysis procedure showing identified dislocation loops from Figure 9. Red loops indicate either edge-on or in-plane a $\langle\mathbf{1 0 0}\rangle$ loops, blue loops indicate a/2 $\langle\mathbf{1 1 1}\rangle$ loops, green loops indicate unidentifiable defects (mostly black dots) while light yellow lines indicate $100 \mathrm{~nm}$ size bins uniformly spaced away from the grain boundary (dashed black line). 
Table 7: Summary of quantified number densities for different dislocation loop types for specific grain boundaries in the $1.8 \mathrm{dpa}, 320^{\circ} \mathrm{C}$ irradiated Alkrothal 720 sample.

\begin{tabular}{|c|c|c|c|c|}
\hline \multirow{2}{*}{\multicolumn{2}{|c|}{ Property }} & \multicolumn{3}{|c|}{ Boundary ID } \\
\hline & & RHAGB 1 & RHAGB 2 & RHAGB 3 \\
\hline \multicolumn{2}{|c|}{ Mis. Angle ( $\left.{ }^{\circ}\right)$} & 46.8 & 40.8 & 52.2 \\
\hline \multicolumn{2}{|c|}{ Mis. Axis [uvw] } & {$\left[\begin{array}{lll}1 & 0 & 3\end{array}\right]$} & {$\left[\begin{array}{lll}0 & -1 & 3\end{array}\right]$} & {$\left[\begin{array}{lll}-3 & 0 & 2\end{array}\right]$} \\
\hline \multicolumn{2}{|c|}{ MDS (nm) } & 22.4 & 15.8 & 16.3 \\
\hline \multicolumn{2}{|c|}{ Peak Zone Distance (nm) } & 175 & 175 & 125 \\
\hline \multicolumn{2}{|c|}{ Number of defects counted } & 1573 & 1872 & 4156 \\
\hline \multirow{6}{*}{$\begin{array}{l}\text { Denuded Zone } \\
(50 \mathrm{~nm} \text { from } \mathrm{GB})\end{array}$} & $d_{a<100>}(n m)$ & $22.8 \pm 6.4$ & $24.8 \pm 6.3$ & $22.8 \pm 8.8$ \\
\hline & $\rho_{\mathrm{a}<100>}\left(\mathrm{m}^{-3}\right)$ & $2.25 \pm 0.71 \times 10^{21}$ & $2.68 \pm 0.81 \times 10^{21}$ & $2.02 \pm 0.54 \times 10^{21}$ \\
\hline & $\mathrm{d}_{\mathrm{a} / 2<111>}(\mathrm{nm})$ & $19.0 \pm 4.4$ & $20.1 \pm 6.3$ & $21.9 \pm 6.3$ \\
\hline & $\rho_{\mathrm{a} / 2<111>}\left(\mathrm{m}^{-3}\right)$ & $4.72 \pm 1.03 \times 10^{21}$ & $6.58 \pm 1.27 \times 10^{21}$ & $5.91 \pm 0.92 \times 10^{21}$ \\
\hline & $\mathbf{d}_{\mathrm{bd}}(\mathrm{nm})$ & $13.5 \pm 6.0$ & $10.7 \pm 4.6$ & $11.8 \pm 5.8$ \\
\hline & $\rho_{b d}\left(m^{-3}\right)$ & $4.50 \pm 1.01 \times 10^{21}$ & $5.61 \pm 1.17 \times 10^{21}$ & $4.61 \pm 0.82 \times 10^{21}$ \\
\hline \multirow{6}{*}{$\begin{array}{l}\text { Peak Zone } \\
\text { (at peak zone } \\
\text { distance) }\end{array}$} & $d_{a<100>}(n m)$ & $10.9 \pm 2.3$ & $10.8 \pm 1.6$ & $14.0 \pm 5$ \\
\hline & $\rho_{\mathrm{a}<100>}\left(\mathrm{m}^{-3}\right)$ & $1.12 \pm 0.50 \times 10^{21}$ & $1.95 \pm 0.69 \times 10^{21}$ & $4.62 \pm 0.82 \times 10^{21}$ \\
\hline & $d_{a / 2<111>}(n m)$ & $11.0 \pm 3.6$ & 9.2 & $13.4 \pm 2.0$ \\
\hline & $\rho_{\mathrm{a} / 2<111>}\left(\mathrm{m}^{-3}\right)$ & $8.99 \pm 4.50 \times 10^{20}$ & $2.44 \times 10^{20}$ & $3.89 \pm 0.75 \times 1021$ \\
\hline & $d_{b d}(n m)$ & $8.2 \pm 1.9$ & $8.6 \pm 1.7$ & $9.8 \pm 3.5$ \\
\hline & $\rho_{\text {bd }}\left(m^{-3}\right)$ & $1.30 \pm 0.17 \times 10^{22}$ & $2.17 \pm 0.23 \times 10^{22}$ & $1.07 \pm 0.12 \times 10^{22}$ \\
\hline \multirow{6}{*}{$\begin{array}{c}\text { Grain Interior } \\
\text { (at } 700 \mathrm{~nm} \text { from } \\
\text { GB) }\end{array}$} & $d_{a<100>}(n m)$ & - & - & $10 \pm 3.8$ \\
\hline & $\rho_{\mathrm{a}<100>}\left(m^{-3}\right)$ & - & - & $1.32 \pm 0.54 \times 10^{21}$ \\
\hline & $\mathbf{d}_{\mathrm{a} / 2<111>}(\mathbf{n m})$ & - & - & - \\
\hline & $\rho_{\mathrm{a} / 2<111>}\left(\mathbf{m}^{-3}\right)$ & - & - & - \\
\hline & $d_{b d}(n m)$ & $8.3 \pm 2.1$ & $7.5 \pm 1.8$ & $8.9 \pm 1.6$ \\
\hline & $\rho_{b d}\left(m^{-3}\right)$ & $3.95 \pm 1.01 \times 10^{21}$ & $6.47 \pm 1.17 \times 10^{21}$ & $9.22 \pm 0.86 \times 10^{21}$ \\
\hline
\end{tabular}

Subscripts: $a<100>, a\langle 100\rangle$ dislocation loops; $a / 2<111>, a / 2\langle 111\rangle$ dislocation loops; bd, black dots

\subsubsection{Identification of $\alpha^{\prime}$ using STEM-EDS}

A preliminary study was conducted using ORNL's FEI F200X Talos to determine if the Cr-rich $\alpha$ ' phase could be detected using high efficiency STEM-EDS spectrum imaging. The sample used for this study was the Alkrothal 720 alloy irradiated to $1.8 \mathrm{dpa}, 320^{\circ} \mathrm{C}$. A RHAGB was tilted edge-on and a $512 \times 512$ pixel spectrum image was acquired. A grain boundary was included in the scan to enable determination if the grain boundary played an effect on the precipitation behavior of $\alpha^{\prime}$ under irradiation. X-ray maps were extracted from the spectrum image and a 3-pixel neighbored averaging filter was applied to observe any 
clustering in the material, as seen in Figure 11. Figure 11 shows regions of $\mathrm{Cr}$ enrichment indicating the capability to observe $\alpha^{\prime}$ in the alloys using STEM-EDS imaging techniques. Furthermore, the color overlay in Figure 11 shows radiation-induced segregation (RIS) at the grain boundary with oscillatory behavior in the $\mathrm{Cr}$ response across the grain boundary. These observations possibly indicates the first identification of $\alpha^{\prime}$ phase and corresponding RIS effects using STEM-EDS techniques. Application of the STEM-EDS technique for $\alpha^{\prime}$ identification will enable further studies to determine whether the $\alpha^{\prime}$ phase is correlated or anti-correlated with other microstructural defects such as dislocation loops and defect clusters. Future PIE activities includes this type of investigation as well as further investigations on the RIS response in the $\mathrm{FeCrAl}$ alloys and whether $\alpha^{\prime}$ denuded zones are observed at higher doses near grain boundaries.
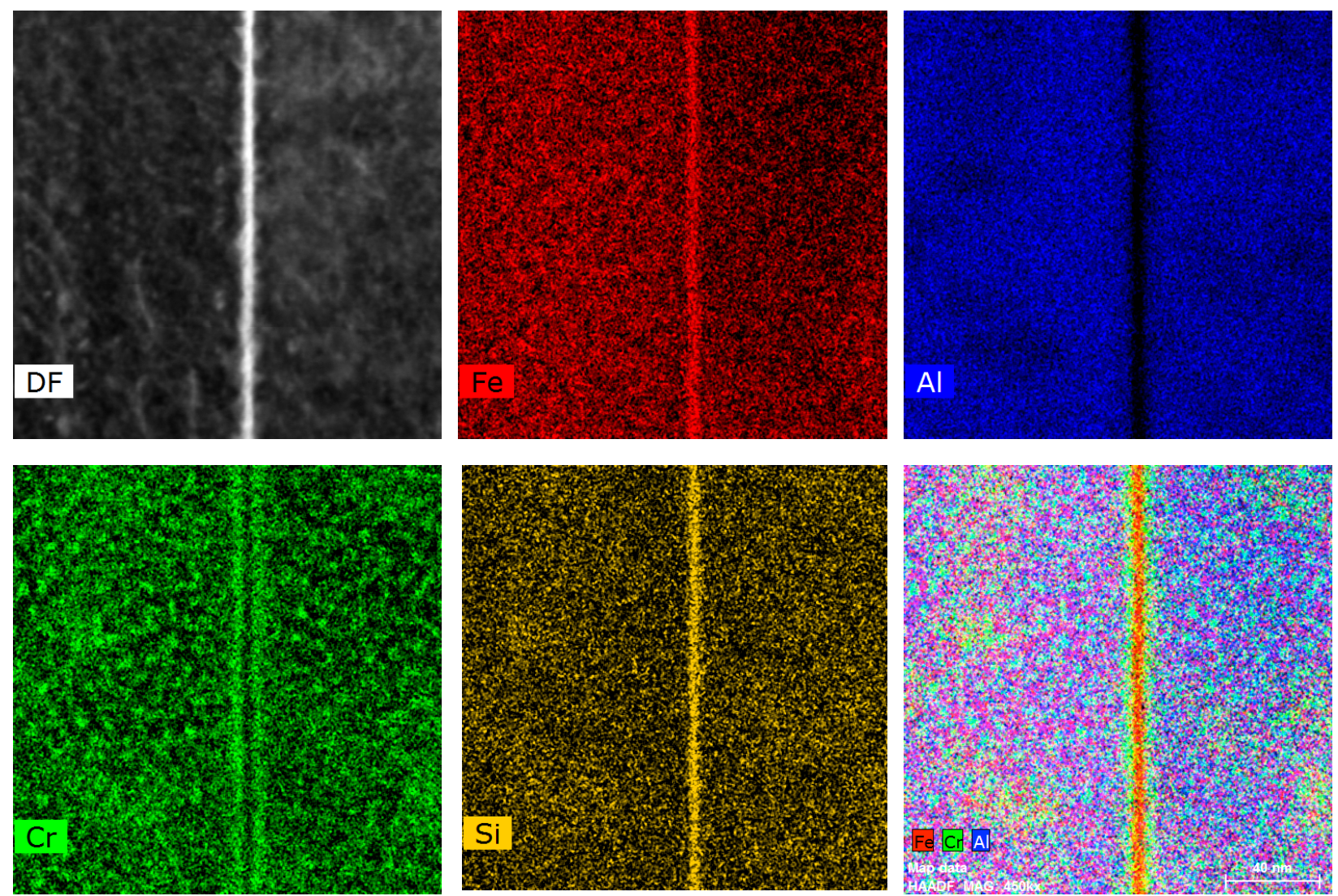

Figure 11: Dark-field STEM image, $x$-ray maps, and color overlay maps derived from a spectrum image on the $1.8 \mathrm{dpa}, 320^{\circ} \mathrm{C}$ irradiated Alkrothal 720 alloy showing $\alpha^{\prime}$ and RIS at a grain boundary. $\mathrm{Cr}$-rich $\alpha^{\prime}$ is observed as clustering the $\mathrm{Cr}$ map and as green dots in the overlay map.

\subsection{Atom Probe Tomography}

The irradiated $\mathrm{FeCrAl}$ alloys (both model and commercial) are expected to experience precipitation of the Cr-rich $\alpha^{\prime}$ given sufficient time, temperature, and radiation dose. Here, of particular interest is the size, number density, volume fraction, and composition of the $\alpha^{\prime}$ phase within the samples. The $\alpha^{\prime}$ phase has nearly identical lattice parameters to the host $\alpha$ phase making it inherently difficult to image using defect contrast based electron microscopy techniques. Therefore, techniques to image and quantify the $\alpha^{\prime}$ must be composition based, such as the STEM-EDS technique discussed previously. Composition is of particular interest as the partitioning of the elements to either the $\alpha^{\prime}$ phase or the $\alpha$ phase could provide insight on how these elements stabilize the microstructural features observed after irradiation. In order to determine the particle composition as well as quantify the size and number density, the APT technique 
was employed. Table 3 summarizes the samples that have been investigated using APT. In short, samples were selected to probe the composition dependencies at the highest dose in the Generation I FeCrAl alloys and the APMT sample while the Fe-18Cr-2.9Al was used to determine dose dependencies by looking at the low, medium, and high dose samples. Additionally, the as-received case of Fe-18Cr-2.9Al sample was also investigated to determine if clustering was present prior to irradiation.

Figure 12 shows an example of a reconstructed atom probe data set of the $7 \mathrm{dpa}, 320^{\circ} \mathrm{C}$ irradiated $\mathrm{Fe}-$ 18Cr-2.9Al specimen, with the Cr-rich $\alpha^{\prime}$ clusters illustrated using 30 at. \% $\mathrm{Cr}$ concentration isosurfaces. Precipitate radii were calculated assuming spherical cluster geometries and radii, number densities, and volume fractions were averaged over all microtips run for a given condition. Table 8 summarizes the resulting quantification for the different Generation $\mathrm{I} \mathrm{FeCrAl}$ alloys irradiated to $7 \mathrm{dpa}, 320^{\circ} \mathrm{C}$ while Table 9 summarizes the determined values as a function of irradiation condition for the $\mathrm{Fe}-18 \mathrm{Cr}-2.9 \mathrm{Al}$ alloy. It is seen that increasing $\mathrm{Cr}$ content while decreasing $\mathrm{Al}$ content results in an increase in the number density of precipitates and a decrease in the average cluster size. Furthermore, the average precipitate composition varies greatly, with $\mathrm{Al}$ additions potentially depressing the equilibrium $\mathrm{Cr}$ content in these precipitates when compared to $\mathrm{FeCr}$ binary systems [25]. In analyzing the variable dose $\mathrm{Fe}-18 \mathrm{Cr}-2.9 \mathrm{Al}$ specimens, it is noted that number density, volume fraction, and $\mathrm{Cr}$ content of clusters increase asymptotically and seem to approach saturation values. It should be noted that there is some temperature variation in the specimens with different nominal damage doses but the overall trends are consistent with literature on irradiated $\mathrm{FeCr}$ alloys [26].

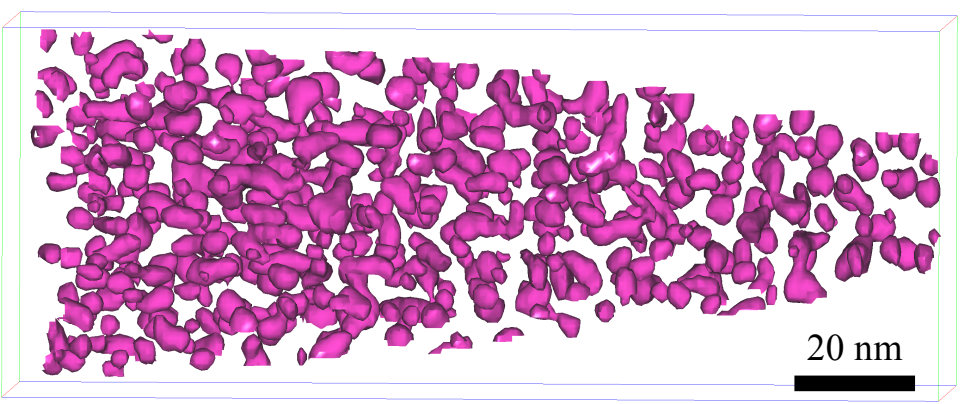

Figure 12: Reconstructed microtip of 7.0 dpa, $320^{\circ} \mathrm{C}$ irradiated $\mathrm{Fe}-18 \mathrm{Cr}-2.9 \mathrm{Al}$ showing $\mathrm{Cr}-$-rich clusters using 30 at\% concentration isosurfaces.

Table 8: Summary of $\alpha^{\prime}$ precipitation behavior vs. FeCrAl composition.

\begin{tabular}{|c|c|c|c|c|c|c|c|c|}
\hline Alloy & $\begin{array}{l}\text { Irr. Dose } \\
\quad \text { (dpa) }\end{array}$ & $\begin{array}{c}\text { Irr. } \\
\text { Temp } \\
\left({ }^{\circ} \mathrm{C}\right)\end{array}$ & $f_{\alpha^{\prime}}$ & $\begin{array}{c}\rho_{\alpha^{\prime}} \\
\left(10^{24} / \mathbf{m}^{3}\right)\end{array}$ & $\begin{array}{c}d_{\alpha^{\prime}} \\
(n \mathbf{m})\end{array}$ & $\begin{array}{c}\text { Avg. Fe } \\
\text { (at.\%) }\end{array}$ & $\begin{array}{c}\text { Avg. Cr } \\
\text { (at.\%) }\end{array}$ & $\begin{array}{c}\text { Avg. Al } \\
\text { (at.\%) }\end{array}$ \\
\hline $\begin{array}{c}\mathrm{Fe}-10 \mathrm{Cr}- \\
4.8 \mathrm{Al}\end{array}$ & 7 & 320 & $\begin{array}{c}0.0089 \pm \\
0.00098\end{array}$ & $\begin{array}{l}1.25 \pm \\
0.352\end{array}$ & $\begin{array}{l}1.74 \pm \\
0.988\end{array}$ & $\begin{array}{c}27.5 \pm \\
8.01\end{array}$ & $\begin{array}{c}66.7 \pm \\
8.78\end{array}$ & $\begin{array}{l}5.8 \pm \\
3.80 \\
\end{array}$ \\
\hline $\begin{array}{c}\mathrm{Fe}-12 \mathrm{Cr}- \\
4.4 \mathrm{Al}\end{array}$ & 7 & 320 & 0.0031 & $\begin{array}{l}1.38 \pm \\
0.158\end{array}$ & $\begin{array}{l}1.46 \pm \\
0.416 \\
\end{array}$ & $\begin{array}{c}23.9 \pm \\
7.85 \\
\end{array}$ & $\begin{array}{c}71.0 \pm \\
8.33\end{array}$ & $\begin{array}{l}5.1 \pm \\
3.56 \\
\end{array}$ \\
\hline $\begin{array}{c}\mathrm{Fe}-15 \mathrm{Cr}- \\
3.9 \mathrm{Al} \\
\end{array}$ & 7 & 320 & $\begin{array}{c}0.0029 \pm \\
0.00045 \\
\end{array}$ & $\begin{array}{c}2.77 \pm \\
0.549 \\
\end{array}$ & $\begin{array}{l}1.22 \pm \\
0.192 \\
\end{array}$ & $\begin{array}{c}18.2 \pm \\
8.11 \\
\end{array}$ & $\begin{array}{c}76.9 \pm \\
8.64 \\
\end{array}$ & $\begin{array}{c}4.9 \pm \\
4.18 \\
\end{array}$ \\
\hline $\begin{array}{c}\mathrm{Fe}-18 \mathrm{Cr}- \\
2.9 \mathrm{Al}\end{array}$ & 7 & 320 & $\begin{array}{c}0.0034 \pm \\
0.00052\end{array}$ & $\begin{array}{l}4.75 \pm \\
0.894\end{array}$ & $\begin{array}{l}1.08 \pm \\
0.164\end{array}$ & $\begin{array}{c}15.3 \pm \\
8.35\end{array}$ & $\begin{array}{c}81.0 \pm \\
8.98\end{array}$ & $\begin{array}{c}3.75 \pm \\
4.31\end{array}$ \\
\hline
\end{tabular}

$f$, volume fraction; $\rho$, number density; $d$, effective diameter 
Table 9: Summary of $\alpha^{\prime}$ precipitation behavior vs. nominal damage dose.

\begin{tabular}{|c|c|c|c|c|c|c|c|c|}
\hline Alloy & $\begin{array}{l}\text { Irr. Dose } \\
\text { (dpa) }\end{array}$ & $\begin{array}{l}\text { Irr. Temp } \\
\quad\left({ }^{\circ} \mathrm{C}\right)\end{array}$ & $f_{\alpha^{\prime}}$ & $\begin{array}{c}\rho_{a^{\prime}} \\
\left(10^{24} / \mathbf{m}^{3}\right)\end{array}$ & $\begin{array}{c}\mathbf{d}_{\boldsymbol{\alpha}^{\prime}} \\
(\mathbf{n m})\end{array}$ & $\begin{array}{c}\text { Avg. Fe } \\
\text { (at.\%) }\end{array}$ & $\begin{array}{c}\text { Avg. Cr } \\
\text { (at.\%) }\end{array}$ & $\begin{array}{c}\text { Avg. Al } \\
\text { (at.\%) }\end{array}$ \\
\hline $\begin{array}{c}\text { Fe-18Cr- } \\
2.9 \mathrm{Al}\end{array}$ & 0.8 & 355 & $\begin{array}{c}0.0011 \pm \\
0.00097\end{array}$ & $\begin{array}{c}0.85 \pm \\
0.954\end{array}$ & $\begin{array}{l}1.28 \pm \\
0.228\end{array}$ & $\begin{array}{c}23.5 \pm \\
8.25\end{array}$ & $\begin{array}{c}71.9 \pm \\
8.79\end{array}$ & $\begin{array}{l}4.6 \pm \\
3.72\end{array}$ \\
\hline $\begin{array}{c}\mathrm{Fe}-18 \mathrm{Cr}- \\
2.9 \mathrm{Al}\end{array}$ & 1.6 & 382 & $\begin{array}{c}0.0028 \pm \\
0.00041\end{array}$ & $\begin{array}{l}3.16 \pm \\
1.045\end{array}$ & $\begin{array}{c}1.18 \pm \\
0.158\end{array}$ & $\begin{array}{c}17.4 \pm \\
8.17\end{array}$ & $\begin{array}{c}79.0 \pm \\
8.60\end{array}$ & $\begin{array}{l}3.6 \pm \\
3.75\end{array}$ \\
\hline $\begin{array}{c}\mathrm{Fe}-18 \mathrm{Cr}- \\
2.9 \mathrm{Al}\end{array}$ & 7 & 320 & $\begin{array}{c}0.0034 \pm \\
0.00052\end{array}$ & $\begin{array}{c}4.75 \pm \\
0.894\end{array}$ & $\begin{array}{c}1.08 \pm \\
0.164\end{array}$ & $\begin{array}{c}15.3 \pm \\
8.35\end{array}$ & $\begin{array}{c}81.0 \pm \\
8.98\end{array}$ & $\begin{array}{c}3.75 \pm \\
4.31\end{array}$ \\
\hline
\end{tabular}

$f$, volume fraction; $\rho$, number density; $d$, effective diameter

\subsection{Small Angle Neutron Scattering}

Small angle neutron scattering (SANS) was employed to complement the APT analysis provided in Section 4.3. There exists a large difference between the neutron coherent scattering lengths of $\mathrm{Fe}$ and $\mathrm{Cr}$ which allows for detailed investigations into the mean size, shape, and number density of $\alpha^{\prime}$. Furthermore, SANS techniques do not exhibit the same aberrations and uncertainties in the data analysis as APT providing a complement/confirmation to the data already presented. Finally, the SANS techniques employed required limited sample preparation and the data collection requires limited effort enabling all irradiation samples to be analyzed in just a few days of beam time at the GP-SANS line at HFIR.

Figure 13a shows changes in scattering intensities above $\mathrm{q} \geq 0.5 \mathrm{~nm}^{-1}$ for the model Fe-18Cr-2.9Al alloy at varying irradiation conditions while Figure $13 \mathrm{~b}$ shows the changes in scattering intensity above $\mathrm{q} \geq 0.5$ $\mathrm{nm}^{-1}$ for the model $\mathrm{FeCrAl}$ alloys irradiated to $1.8 \mathrm{dpa}, 382^{\circ} \mathrm{C}$. In Figure 13, a clear change in intensity is observed for both increasing $\mathrm{Cr}$ content with constant irradiation condition and for increasing irradiation dose with constant $\mathrm{Cr}$ content. The observed scattering intensities are qualitatively similar to responses seen in aged $\mathrm{FeCrAl}$ alloys or irradiated $\mathrm{FeCr}$ alloys by several authors [26-29]. These changes in scattering intensity have been attributed to precipitation of isolated Cr-rich $\alpha^{\prime}$ surrounded by a spherical exclusion volume depleted in $\mathrm{Cr}$. To provide quantitative assessment of the scattering intensities for all samples, a spherical exclusion model was applied to the SANS data. A reasonable fit was found in the range of $0.5<\mathrm{q}<2.0 \mathrm{~nm}^{-1}$, as shown in Figure 6, that further confirms that the scattering signal from the nanometer-size precipitates is indicative of $\mathrm{Cr}$-rich $\alpha^{\prime}$ in the irradiated $\mathrm{FeCrAl}$ alloys.

Table 10 summarizes the calculated volume fraction, size, and number density of the $\alpha$ precipitates based on the best-fit model applied in Figure 6 . The data provided in Table 10 for the $1.8 \mathrm{dpa}, 382^{\circ} \mathrm{C}$ samples is reproduced from Field et al. [11]. The data in Table 10 indicates the volume fraction and number density of the $\alpha^{\prime}$ precipitates had a nearly linear increase with a rise in the $\mathrm{Cr}$ content and minor changes in the $\mathrm{Al}$ content in the alloys when the irradiation condition was held constant. Given this, the size the precipitates were less affected with varying alloy composition at the same irradiation condition. This result is in reasonable agreement with the findings presented in Section 4.3 for the APT analysis. At the highest observed dose, $7 \mathrm{dpa}$, the high $\mathrm{Cr} \mathrm{FeCrAl}$ alloys ( $>13 \mathrm{wt} . \% \mathrm{Cr}$ ) appear to have saturated in number density indicating that with sufficient $\mathrm{Cr}$ content a saturation point exists in the precipitation of the $\mathrm{Cr}$-rich $\alpha^{\prime}$ phase. With increasing radiation dose (dpa) and relatively constant temperature, the size of the $\alpha^{\prime}$ precipitates tended to enlarge (coarsen) while the number density tended to decrease. These trends are better reflected in Figure 14. Based on Figure 14, it appears that at doses near 7 dpa the samples with $\mathrm{Cr}$ 
contents greater than $>13$ wt.\% Cr have reached steady state with stabilized size and number density values based on the SANS analysis.
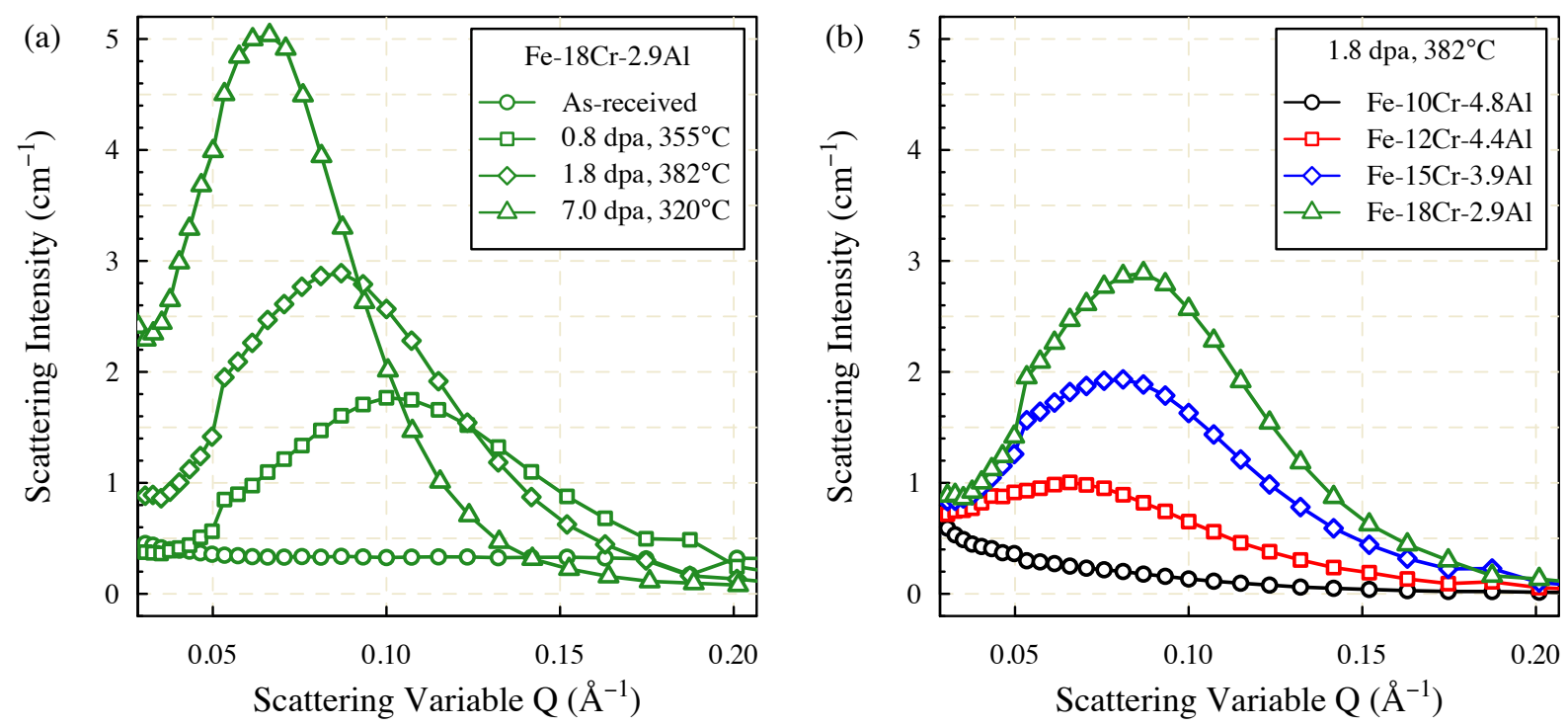

Figure 13: Scattered intensities of model FeCrAl specimens obtained from SANS after irradiation, (a) for the Fe-19Cr-2.9Al with changing irradiation conditions and (b) for constant irradiation conditions but varying alloy content in the model $\mathrm{FeCrAl}$ alloys.

Table 10: Summary of Cr-rich $\alpha^{\prime}$ size and number density determined using SANS in FeCrAl specimens irradiated in the HFIR reactor. Data for the $1.8 \mathrm{dpa}, 382^{\circ} \mathrm{C}$ from Field et al. [11].

\begin{tabular}{|c|c|c|c|c|c|}
\hline Alloy & $\begin{array}{l}\text { Irradiation } \\
\text { Dose (dpa) }\end{array}$ & $\begin{array}{l}\text { Irradiation } \\
\text { Temp }\left({ }^{\circ} \mathrm{C}\right)\end{array}$ & $f_{\mathbf{a}^{\prime}}$ & $\rho_{\alpha^{\prime}}\left(m^{-3}\right)$ & $\begin{array}{c}d_{\alpha^{\prime}} \\
(\mathbf{n m})\end{array}$ \\
\hline \multirow{3}{*}{$\mathrm{Fe}-10 \mathrm{Cr}-4.8 \mathrm{Al}$} & 0.8 & 355 & 0.007 & $2.1 \times 10^{23}$ & 4.1 \\
\hline & 1.8 & 382 & 0.009 & $2.0 \times 10^{23}$ & 4.4 \\
\hline & 7 & 320 & 0.003 & $5.7 \times 10^{22}$ & 4.8 \\
\hline \multirow{3}{*}{$\mathrm{Fe}-12 \mathrm{Cr}-4.4 \mathrm{Al}$} & 0.3 & 334 & 0.026 & $2.4 \times 10^{24}$ & 2.7 \\
\hline & 1.8 & 382 & 0.017 & $4.3 \times 10^{23}$ & 4.3 \\
\hline & 7 & 320 & 0.05 & $2.0 \times 10^{24}$ & 3.7 \\
\hline \multirow{3}{*}{ Fe-15Cr-3.9Al } & 0.3 & 334 & 0.131 & $2.0 \times 10^{25}$ & 2.3 \\
\hline & 1.8 & 382 & 0.08 & $1.9 \times 10^{24}$ & 4.3 \\
\hline & 7 & 320 & 0.119 & $4.8 \times 10^{24}$ & 3.6 \\
\hline \multirow{3}{*}{ Fe-18Cr-2.9Al } & 0.8 & 355 & 0.191 & $1.3 \times 10^{25}$ & 3.0 \\
\hline & 1.8 & 382 & 0.18 & $6.8 \times 10^{24}$ & 3.7 \\
\hline & 7 & 320 & 0.124 & $1.8 \times 10^{24}$ & 5.1 \\
\hline \multirow{3}{*}{ Alkrothal 720} & 0.8 & 355 & 0.123 & $3.4 \times 10^{24}$ & 4.1 \\
\hline & 1.8 & 382 & 0.078 & $2.2 \times 10^{24}$ & 4.1 \\
\hline & 7 & 320 & 0.081 & $7.7 \times 10^{23}$ & 5.9 \\
\hline \multirow{3}{*}{ APMT } & 0.3 & 334 & 0.142 & $2.0 \times 10^{25}$ & 2.4 \\
\hline & 1.8 & 382 & 0.155 & $1.4 \times 10^{25}$ & 2.8 \\
\hline & 7 & 320 & 0.129 & $2.0 \times 10^{24}$ & 5.0 \\
\hline
\end{tabular}


$f$, volume fraction; $\rho$, number density; $d$, effective diameter
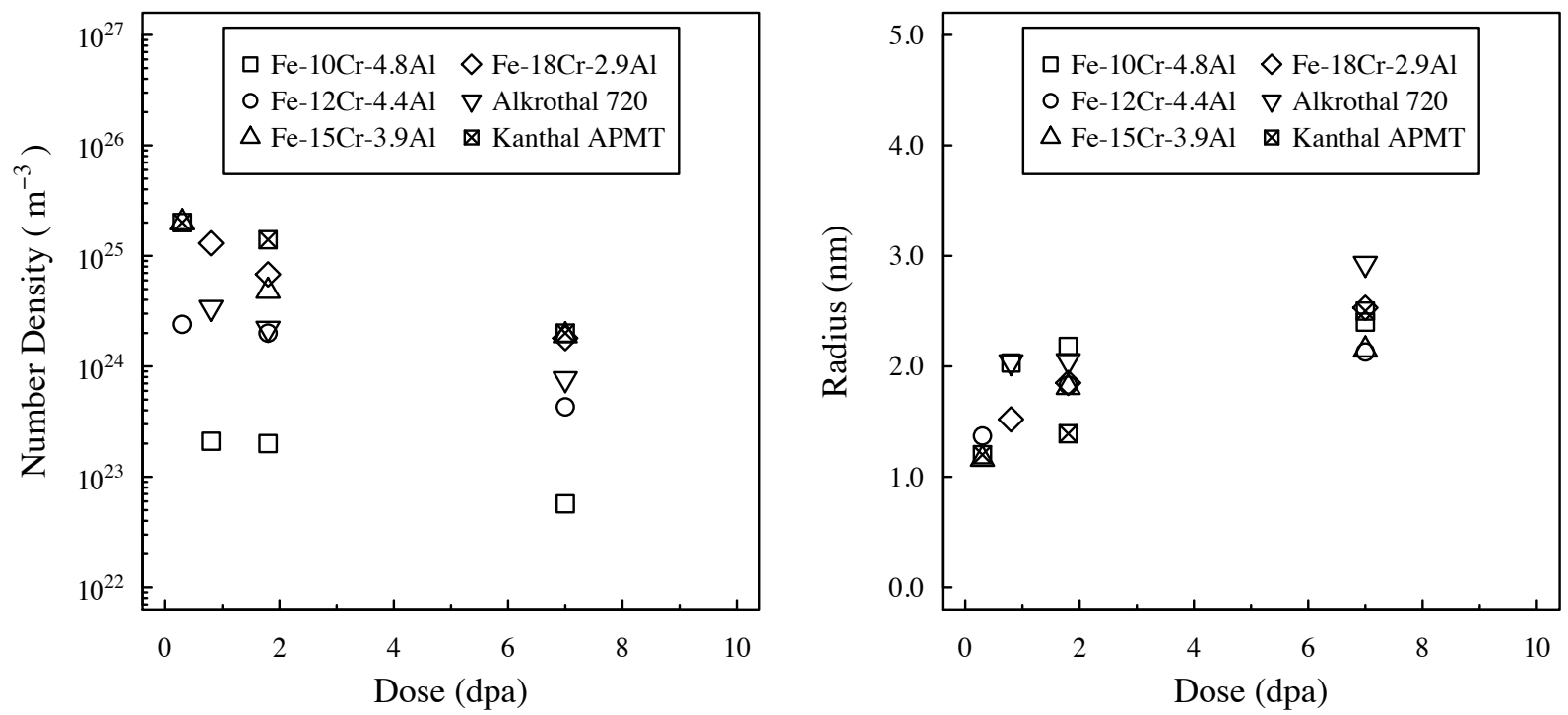

Figure 14: Trends on size and number density of $\alpha^{\prime}$ precipitates as a function of irradiation dose as determined by SANS.

\section{DISCUSSION}

The presence of $a / 2\langle 111\rangle$ dislocation loops, $a\langle 100\rangle$ dislocation loops, black dots, and $\alpha^{\prime}$ precipitates is consistent with the expected microstructure based on results from irradiated $\mathrm{FeCr}$ alloys [30-34]. As discussed in previously published reports $[10,11]$, no clear trends were observed for changing composition for the formation of dislocation loops for those alloys currently characterized. This result is similar to those reported in literature for neutron-irradiated $\mathrm{FeCr}$ alloys [33]. The trend of increasing $\alpha^{\prime}$ precipitation with increasing $\mathrm{Cr}$ content for both APT and SANS investigations is consistent with literature on neutron irradiated $\mathrm{FeCr}$ alloys as well. For example, Bachhav et al. [30-32] investigated a series of model $\mathrm{FeCr}$ alloys irradiated to $1.82 \mathrm{dpa}$ at $290^{\circ} \mathrm{C}$ using APT. Bachhav's study showed precipitation of $\alpha^{\prime}$ to be linearly dependent on Cr composition, with an upper limit in number density near $5.3 \times 10^{24} \mathrm{~m}^{-3}$ in the $\mathrm{Fe}-18 \mathrm{Cr}$ specimen, a result remarkably similar to the result presented here for similar irradiation conditions. Also, the trends with increase dose, which also resulted in increased time at temperature, for the SANS results aligns remarkably well for aged and irradiated $\mathrm{FeCr}$ and $\mathrm{FeCrAl}$ alloys as seen in Figure 15. The solute partitioning observed using APT for all samples is identical to the phenomena observed by Capdevila et al. [25, 35] and suggests the $\mathrm{Al}$ and $\mathrm{Cr}$ partitioning are coupled and therefore governs the overall $\alpha^{\prime}-\alpha$ phase separation. This is further corroborated by the results of Kobayashi and Takasugi [36] who indicated that increasing the Al content can impact the formation of $\alpha^{\prime}$ precipitates in the Fe-rich corner of the FeCrAl system.

The APT and SANS data presented for the precipitation of $\alpha^{\prime}$ was found to be partially overlapping but with some discrepancies. Similar responses between the two techniques have been reported for precipitation in reactor pressure vessel (RPV) steels. In both cases, the SANS results tended to estimate larger precipitates than those detected using APT. Meslin et al. [37] attributed this to a detection limit in SANS nearing $0.5 \mathrm{~nm}$. The SANS analysis technique used here is also sensitive to the assumed scattering cluster composition; large variation in the composition can significantly change the volume fraction and number densities. As discussed in Section 4.3, the composition of the clusters via APT were found to be 
non-constant based on irradiation dose and/or alloy composition although it was assumed they were for the SANS analysis. Further refinement of the SANS data could be completed by using compositions outputted by APT although some bias is intrinsic in benchmarking the SANS data in this manner as APT can be effected by local magnification and trajectory aberrations resulting in skewed compositions results. Further sensitivities in the APT analysis could also be contributing to the discrepancies between techniques. Here, the maximum separation distance technique was used to quantify the clusters size, volume fraction, and number density. This quantification technique is sensitive to parameters selected, such as expected maximum separation distance between clustered atoms $\left(\mathrm{d}_{\max }\right)$ and the minimum number of atoms composing a cluster $\left(\mathrm{N}_{\text {min }}\right)$. For both factors, a small change in their values can drastically skew results. Here, the values selected for this study were consistent based on preselected criteria. Further work could include a more parametric analysis on the contributing factors towards the quantified values of size, number density, and volume fraction for both techniques enabling better agreement between the two techniques.
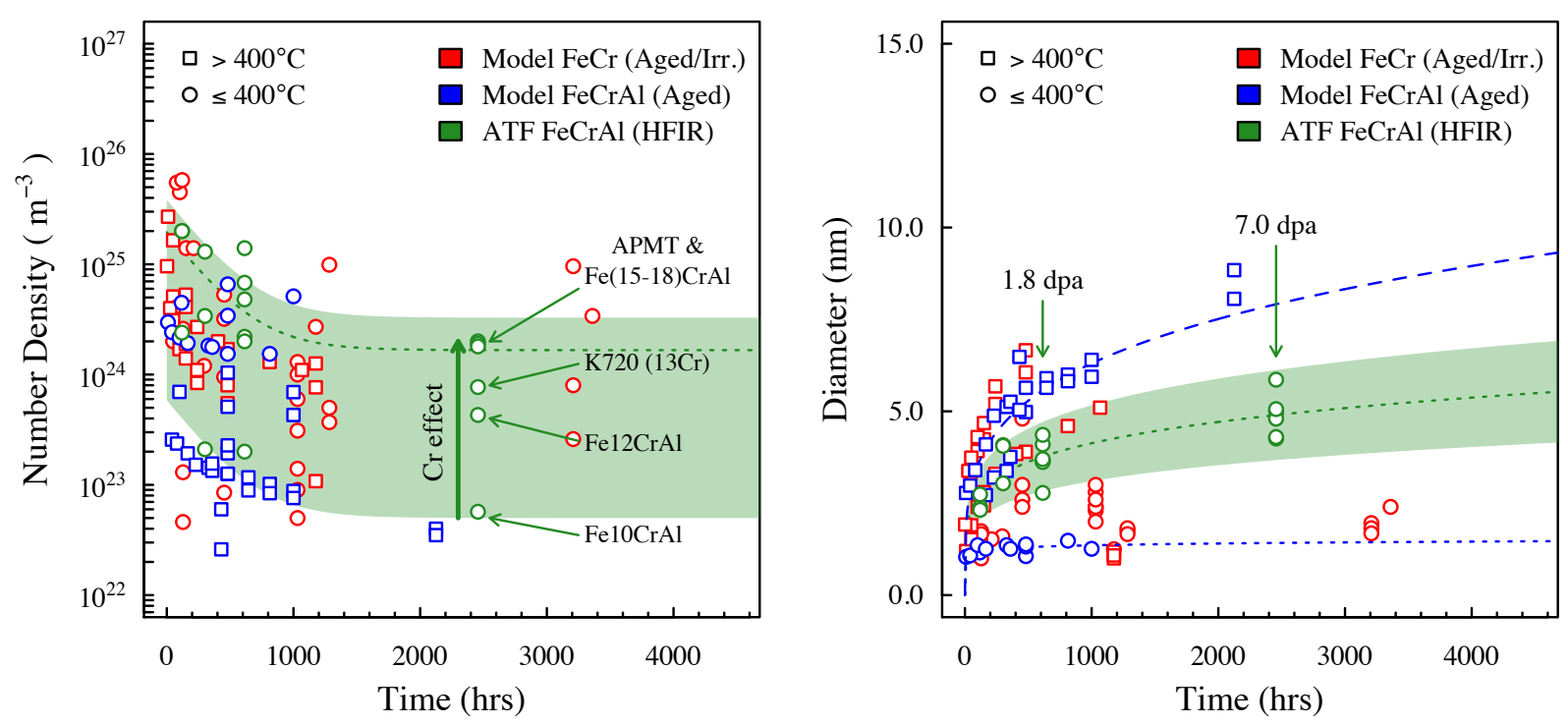

Figure 15: Comparison of SANS results with those published in literature. Green polygon is based on the data presented in Table 10. Blue lines indicate established trends from aged FeCrAl alloys [29]. All other literature results complied from [26, 30-32, 38-42].

The Alkrothal $7201.8 \mathrm{dpa}, 320^{\circ} \mathrm{C}$ sample provides interesting insight into the role of existing microstructure (grain boundaries and dislocation networks) on the radiation tolerance and hardening of the $\mathrm{FeCrAl}$ alloys class. The observation of a peak zone near a grain boundary that is roughly ten times the average minimum separation distance for dislocation loops is similar to observations on cavity formation in a range of materials including neutron irradiated $\mathrm{Al}$ and $\mathrm{Cu}-\mathrm{Ni}$ alloys $[43,44]$. This phenomenon suggests that grain boundaries are acting as defect sinks for the irradiated FeCrAl alloys that are further corroborated by the detected RIS in the same sample shown in Figure 11. RIS has been shown to be the result of preferential coupling of solute species to the defect flux at defect sinks such as grain boundaries. The lack of the observed peak zone in the Generation I FeCrAl alloys suggests that the dislocation cell network introduced from the cold working procedure could be suppressing the observed grain boundary effect or that the grain sizes are drastically different between the Alkrothal 720 and model FeCrAl alloys. Further investigations are on going to determine the variance between the commercial and Generation I dislocation loop response near grain boundaries. The preliminary results here suggest that microstructural control could be used to enhance the radiation tolerance and hence reduce the hardening and embrittlement of the FeCrAl alloy class. 
Of primary interest for this report is how the discussed trends or lack of trends in the irradiated microstructure lead to radiation hardening and embrittlement. The results presented in Figure 8 and Table 5 show increasing the $\mathrm{Cr}$ content of the alloy results in increased hardening and when the factor of prior cold work is accounted for; increasing dose also increases the radiation hardening of the material. To further explore the relationships between microstructure and mechanical properties the well-characterized $1.8 \mathrm{dpa}, 382^{\circ} \mathrm{C}$ Generation I FeCrAl alloys have been modeled using the dispersed barrier-hardening model, as reported previously [11]. This technique enables the determination of the significant microstructural features impacting the radiation hardening. This report found that $\alpha$ precipitates, when considered as a single precipitate, have the lowest contribution to hardening but when the number density of the precipitates reach a sufficiently high number density $\left(\geq 10^{24} \mathrm{~m}^{-3}\right)$, the hardening response of the $\mathrm{FeCrAl}$ alloys is dominated by them. This coupling between the number density of $\alpha^{\prime}$ precipitates and $\mathrm{Cr}$ content of the alloys was determined to be the leading factor in the Cr composition dependencies in the hardening response of the alloys. Other microstructural features such as dislocation loops and line dislocations were found to also contribute to the hardening response but when they exist in low number density their contribution is insignificant.

An open ended question remains on the embrittlement of FeCrAl alloys after irradiation. To date, no fracture toughness studies have been completed on irradiated $\mathrm{FeCrAl}$ alloys but based on the extensive database in RPV and reduced-activation ferritic/martensitic (RAFM) steels some knowledge can be inferred on the embrittlement of FeCrAl alloys after irradiation. For example, Sokolov et al. investigated the fracture toughness shift $\left(\Delta \mathrm{T}_{\mathrm{o}}\right)$ and hardening response $\left(\Delta \sigma_{\mathrm{y}}\right)$ of several RAFM steels and compared the results to the established database on RPV steels [45]. Sokolov and coauthors showed that typically a linear relationship can be established for both materials systems, where $\Delta \mathrm{T}_{\mathrm{o}}=0.3 \Delta \sigma_{\mathrm{y}}$ for RAFM steels and $\Delta \mathrm{T}_{\mathrm{o}}=0.7 \Delta \sigma_{\mathrm{y}}$ for RPV steels. The discrepancy in the coefficient of relationship for the two material systems could be the result of either sub-sized specimen issues or inherent difference in the hardening/embrittlement mechanisms for the two systems. Either way, the results of Sokolov et al. indicate a linear relationship between the radiation-induced hardening and fracture toughness shift for several Fe-based alloys

The linear relationship established between the fracture toughness shift and hardness response was primarily completed on samples with little microstructural analysis. Other work completed by Dubuisson et al. [40] evaluated the microstructure and change in the ductile to brittle transition temperature $(\triangle \mathrm{DBTT})$ in several ferritic FeCr alloys after irradiation. In particular, alloy F17, a cold worked 17.3 wt. $\% \mathrm{Cr}$ ferritic alloy, was found to have it's $\triangle \mathrm{DBTT}$ correlated to the $\alpha^{\prime}$ precipitation. In general the $\triangle \mathrm{DBTT}$ increased with increasing number density of precipitates and the size decreases. Based on the data presented by Dubuisson et al., a simple power-law relationship can be developed to predict the $\triangle \mathrm{DBTT}$ based on the $\alpha^{\prime}$ precipitation where $\triangle \mathrm{DBTT}=.003\left(\rho_{\alpha^{\prime}}\right)^{0.227}$. Based on this relationship and the data presented in Table 10, the $\triangle \mathrm{DBTT}$ for the irradiated FeCrAl alloys can be predicted. Several assumptions are inherent with such analysis. The primary assumption is the dislocation loops and networks can contribute to the embrittlement of the alloys but such effect is insignificant in comparison to the embrittlement induced by precipitation of $\alpha^{\prime}$. Such assumption seems reasonably safe, as the precipitation of $\alpha^{\prime}$ has been shown to significantly embrittle $\mathrm{FeCr}$ and $\mathrm{FeCrAl}$ alloys during thermal aging experiments where dislocation loop formation is not present. Furthermore, as shown by the dispersed barrier hardening model, the $\alpha$ ' precipitation dominates the hardening response which has been shown to be proportional to changes in the fracture toughness as described before.

To evaluate the viability of this analysis and the overarching assumptions, the predicted shifts in $\triangle \mathrm{DBTT}$ can be compared to the measured $\Delta \sigma_{\mathrm{y}}$ for the alloys to determine if a linear relationship similar to the one proposed by Sokolov et al. can be reproduced. It should be noted that although the $\triangle \mathrm{DBTT}$ and $\Delta \mathrm{T}_{\mathrm{o}}$ could both be used to quantify embrittlement, they are not a perfect 1:1 relationship [45, 46]. Figure 16 shows the anticipated $\triangle \mathrm{DBTT}$ based on the empirical relationship derived from the Dubuisson et al. data [40] 
with correspondence to the experimentally measured $\Delta \sigma_{\mathrm{y}}$ for the alloys in this study. As seen in Figure 16 , the relationship is scattered and difficult to determine if linearity exists. This could be the result of experimental error in the SANS analysis, as discussed previously, and/or the difference in the characterization technique between this study and that of Dubuisson et al. If one was to assume a linear relationship to the data in Figure 16-dashed line in figure, the coefficient of relationship for FeCrAl systems tends to not be the same as either the RPV or RAFM steels. Here, the coefficient is predicted to be significantly higher, but again the $\triangle \mathrm{DBTT}$, although analogous to $\Delta \mathrm{T}_{\mathrm{o}}$ is not 1:1. For FeCr alloys, literature has shown the $\triangle \mathrm{DBTT}$ tends to underestimate the $\Delta \mathrm{T}_{\mathrm{o}}$ values and hence the coefficient of relationship found in Figure 16 could be lower for $\mathrm{FeCrAl}$ alloys. It should also be noted that the predicted shifts in the DBTT in Figure 16 seem extremely high. The Dubuisson data was derived from relatively low number densities of $\alpha^{\prime}$ where the data shown in Figure 16 has number densities at least one if not two orders of magnitude higher. Potentially, an upper limit exists on the DBTT shift and the relationship inferred from the Dubuisson data could be incorrect, or at least incomplete.

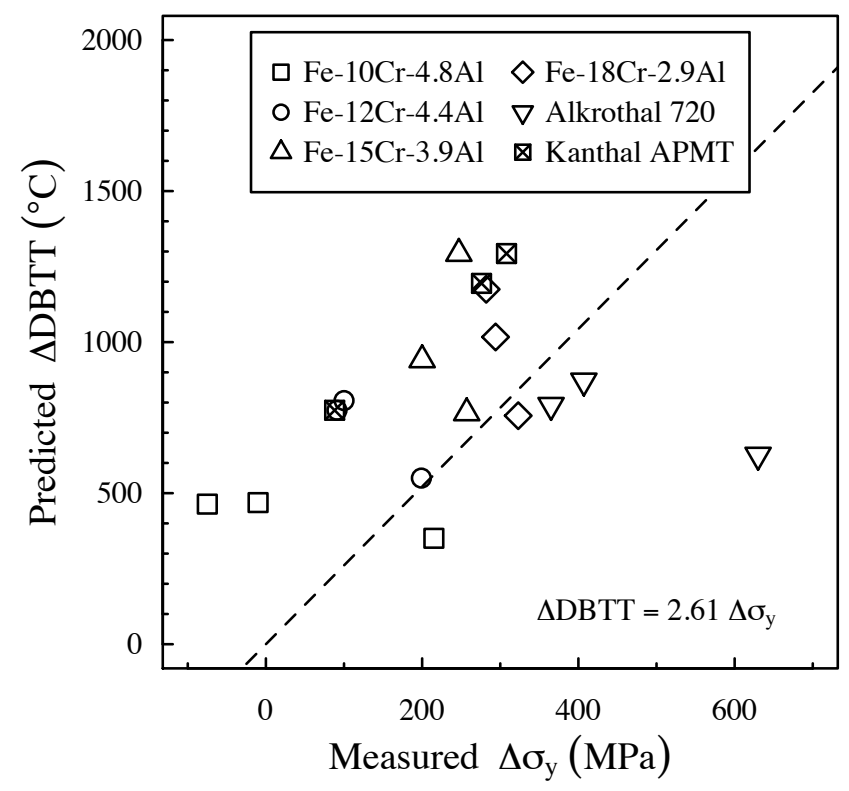

Figure 16: Predicted change in ductile to brittle transition temperature for irradiated FeCrAl based on an empirically established relationship and it's alignment with the observed change in yield stress.

Clearly, further work is needed to confirm the validity of the analysis and the statements made here. But, if the predicted values of $\triangle \mathrm{DBTT}$ are shown to hold true for the FeCrAl system or to be lower even by a factor of two, severe embrittlement of the alloys could be expected after irradiation and the DBTT for the alloys could reach temperatures well above room temperature values. Furthermore, if the proposed mechanism for embrittlement is validated then it would also imply the embrittlement of FeCrAl alloys (either model or commercial) is strongly dependent on the alloy composition (primarily $\mathrm{Cr}$ and/or $\mathrm{Al}$ ) with lower $\mathrm{Cr}$ and high $\mathrm{Al}$ content alloys exhibiting significantly less embrittlement under irradiation due to the reduced precipitation of $\alpha^{\prime}$.

\section{FUTURE WORK}

As stated in Section 5, a database on the embrittlement of FeCrAl alloys currently does not exist but knowledge on $\mathrm{FeCr}$ alloys can be leveraged to infer expected behavior. To overcome this deficiency and 
eliminate ambiguity in the analysis in Section 5, a series of irradiation campaigns have been initiated to specifically irradiate fracture toughness samples of varying FeCrAl composition. The full details on this irradiation program have been reported previously [47]. To summarize, an irradiation capsule has been designed to be irradiated in the HFIR at three different irradiation temperatures and two different damage doses. This capsule will house two different alloys and use M4-PCVVN multi-notch bend bar specimens. The alloys selected include Generation II engineering grade FeCrAl alloys; one alloy being a $\mathrm{Fe}-10 \mathrm{Cr}$ 6Al-2Mo and the other being a Fe-13Cr-6Al-2Mo alloy. The alloys were selected to probe the $\mathrm{Cr}$ composition dependencies on the precipitation of $\alpha^{\prime}$ and hence the composition dependencies on the embrittlement of $\mathrm{FeCrAl}$ alloys. Currently, the irradiation target capsules are targeted to begin irradiation in cycle 462 in the HFIR on October $6^{\text {th }}, 2015$. Based on this insertion date, the last capsule will be released in early January 2017. Extensive PIE will be conducted including determination of the $\Delta \mathrm{T}_{\mathrm{o}}$ values for the irradiated alloys as well as microstructural features contributing to any detected changes in the fracture toughness of the alloys. For further information, the reader is referred to the report published by Field et al. [47].

\section{CONCLUSIONS}

An extensive series of irradiations followed by PIE has been completed on a select set of Generation I $\mathrm{FeCrAl}$ alloys and two commercial FeCrAl alloys to evaluate the radiation performance of this alloy class at or near LWR relevant conditions. To-date PIE, which includes mechanical and microstructural investigations, have shown radiation hardening in the alloys is primarily composition dependent due to the formation of the Cr-rich $\alpha^{\prime}$ being composition dependent. Other radiation induced/enhanced microstructural features such as dislocation loops were observed to contribute to the observed hardening response, but limited affect on composition for these features were observed. Microstructural features, such as grain boundaries, grain size, and/or pre-existing dislocation networks were found to potentially influence the dislocation loop formation under irradiation while grain boundaries were also found to exhibit features indicative of radiation-induced segregation. Several trends besides composition were also observed, including increasing radiation dose (or, time at temperature) promoted changes in the size and number density of the Cr-rich $\alpha^{\prime}$ precipitates. Based on the microstructural analysis, performed tensile testing, and prior knowledge from $\mathrm{FeCr}$ literature it was hypothesized that the formation of the $\mathrm{Cr}$-rich $\alpha^{\prime}$ precipitates could lead to significant radiation-induced embrittlement in the alloys, and this could be composition dependent, a result which would mirror the trends observed for radiation-induced hardening. To further understand the controlling factors for radiation embrittlement in $\mathrm{FeCrAl}$ alloys, a series of irradiation experiments have been design and will be performed.

\section{REFERENCES}

[1] S.J. Zinkle, K.A. Terrani, J.C. Gehin, L.J. Ott, L.L. Snead, Accident tolerant fuels for LWRs: A perspective, Journal of Nuclear Materials, 448 (2014) 374-379.

[2] B.A. Pint, K.A. Terrani, M.P. Brady, T. Cheng, J.R. Keiser, High temperature oxidation of fuel cladding candidate materials in steam-hydrogen environments, Journal of Nuclear Materials, 440 (2013) $420-427$.

[3] B.A. Pint, K.A. Unocic, K.A. Terrani, The effect of steam on the high temperature oxidation behavior of alumina-forming alloys, Materials at High Temperature, 32 (2014) 28-35.

[4] B.A. Pint, K.A. Terrani, Y. Yamamoto, L.L. Snead, Material Selection for Accident Tolerant Fuel Cladding, Accepted in - Metallurgical and Mateirals Transactions E, (2015). 
[5] Y. Yamamoto, B.A. Pint, K.A. Terrani, K.G. Field, L.L. Snead, M3FT-13OR0202291: Development of improved ATF engineering alloy - CALPHAD calculations and initial billet production, in, Oak Ridge National Laboratory, Oak Ridge, TN, 2013.

[6] Y. Yamamoto, Y. Yang, K.G. Field, K.A. Terrani, B.A. Pint, L.L. Snead, M3FT-14OR0202232: Letter Report Documenting Progress of Second Generation ATF FeCrAl Alloy Fabrication, in, Oak Ridge National Laboration, Oak Ridge, TN, 2014.

[7] Y. Yamamoto, Y. Yang, K.G. Field, K.A. Terrani, B.A. Pint, L.L. Snead, Report on the development of 2nd generation ATF FeCrAl alloys, in, Oak Ridge National Laboratory, Oak Ridge, TN, 2014.

[8] Y. Yamamoto, B.A. Pint, K.A. Terrani, K.G. Field, L.L. Snead, Development and property evaluation of nuclear grade wrought $\mathrm{FeCrAl}$ fuel cladding for light water reactors, In-preparation for journal submission, (2015).

[9] Y. Yamamoto, K.G. Field, L.L. Snead, Optimization of Nuclear Grade FeCrAl Fuel Cladding for Light Water Reactors, in: Technical Meeting on Accident Toelrant Fuel Concepts for Light Water Reactors, IAEA, Oak Ridge National Laboratory, 2015.

[10] K.G. Field, X. Hu, K. Littrell, Y. Yamamoto, R.H. Howard, L.L. Snead, Stability of Model FeCrAl Alloys Under The Presence of Neutron Radiation, in, Oak Ridge National Laboratory, Oak Ridge, TN, 2014, pp. 1-26.

[11] K.G. Field, X. Hu, K.C. Littrell, Y. Yamamoto, L.L. Snead, Radiation tolerance of neutron-irradiated model Fe-Cr-Al alloys, Journal of Nuclear Materials, 465 (2015) 746-755.

[12] K.G. Field, M.N. Gussev, Y. Yamamoto, L.L. Snead, Deformation behavior of laser welds in high temperature oxidation resistant $\mathrm{Fe}-\mathrm{Cr}-\mathrm{Al}$ alloys for fuel cladding applications, Journal of Nuclear Materials, 454 (2014) 352-358.

[13] M. Snead, L.L. Snead, K.A. Terrani, K.G. Field, A. Worrall, K.R. Robb, Y. Yamamoto, J. Powers, S. Dryepondt, B.A. Pint, X. HU, Technology Implementation Plan ATF FeCrAl Cladding for LWR Application, in, Oak Ridge National Laboratory, Oak Ridge, TN, 2014.

[14] B.A. Pint, K.A. Unocic, K.A. Terrani, Steam Oxidation of FeCrAl and SiC in the SATS, in, Oak Ridge National Laboratory, 2015.

[15] Y. Yamamoto, M.N. Gussev, B.K. Kim, T.S. Byun, Optimized properties on base metal and thinwalled tube of Generation II ATF FeCrAl, in, Oak Ridge National Laboratory, 2015.

[16] A.A. Campbell, W.D. Porter, Y. Katoh, L.L. Snead, Method for Analyzing Passive SiC

Thermometry with a Continuous Dilatometer to Determine Irradiation Temperature, Submitted to Journal of Nuclear Materials, (2015).

[17] G.D. Wignall, K.C. Littrell, W.T. Heller, Y.B. Melnichenko, K.M. Bailey, G.W. Lynn, D.A. Myles, V.S. Urban, M.V. Buchanan, D.L. Selby, P.D. Butler, The $40 \mathrm{~m}$ general purpose small-angle neutron scattering instrument at Oak Ridge National Laboratory, Journal of Applied Crystallography, 45 (2012) 990-998.

[18] C.M. Parish, K.G. Field, A.G. Certain, J.P. Wharry, Application of STEM characterization for investigating radiation effects in BCC Fe-based alloys, Journal of Materials Research, 30 (2015) 12461274. 
[19] D.B. Williams, C.B. Carter, Transmission Electron Microscopy: A Textbook for Materials Science, 2 ed., Springer, New York, 2009.

[20] S.J. Zinkle, Y. Matsukawa, Observation and analysis of defect cluster production and interactions with dislocations, Journal of Nuclear Materials, 329-333 (2004) 88-96.

[21] N. Yoshida, M. Kiritani, F.E. Fujita, Electron radiation damage of iron in high voltage electron microscope, Journal of the Physical Society of Japan, 39 (1975) 170-179.

[22] S. Kojima, S. Zinkle, Radiation hardening in neutron-irradiated polycrystalline copper: Barrier strength of defect clusters, Journal of Nuclear Materials, 179-181 (1991) 982-985.

[23] B. Yao, D.J. Edwards, R.J. Kurtz, TEM characterization of dislocation loops in irradiated bcc Febased steels, Journal of Nuclear Materials, 434 (2013) 402-410.

[24] H.-H. Jin, Fabrication of a TEM sample of ion-irradiated material using focused ion beam microprocessing and low-energy Ar ion milling, Journal of Electron Microscopy, 59 (2010) 463-468.

[25] C. Capdevila, M.K. Miller, J. Chao, Phase separation kinetics in a Fe-Cr-Al alloy, Acta Materialia, 60 (2012) 4673-4684.

[26] M.H. Mathon, Y. de Carlan, G. Geoffroy, X. Averty, A. Alamo, C.H. de Novion, A SANS investigation of the irradiation-enhanced $\alpha-\alpha^{\prime}$ phases separation in 7-12 Cr martensitic steels, Journal of Nuclear Materials, 312 (2003) 236-248.

[27] Z. Száraz, G. Török, V. Kršjak, P. Hähner, SANS investigation of microstructure evolution in high chromium ODS steels after thermal ageing, Journal of Nuclear Materials, 435 (2013) 56-62.

[28] A. Ulbricht, C. Heintze, F. Bergner, H. Eckerlebe, SANS investigation of a neutron-irradiated Fe9at\%Cr alloy, Journal of Nuclear Materials, 407 (2010) 29-33.

[29] S. Messoloras, B.C. Pike, R.J. Stewart, C.G. Windsor, Precipitation in iron-chromium-aluminium alloys, Metal Science, 18 (1984) 311-321.

[30] M. Bachhav, G. Robert Odette, E.A. Marquis, $\alpha^{\prime}$ precipitation in neutron-irradiated Fe-Cr alloys, Scripta Materialia, 74 (2014) 48-51.

[31] M. Bachhav, G. Robert Odette, E.A. Marquis, Microstructural changes in a neutron-irradiated Fe15at.\%Cr alloy, Journal of Nuclear Materials, 454 (2014) 381-386.

[32] M. Bachhav, L. Yao, G. Robert Odette, E.A. Marquis, Microstructural changes in a neutronirradiated Fe-6at.\%Cr alloy, Journal of Nuclear Materials, 453 (2014) 334-339.

[33] Y. Katoh, A. Kohyama, D. Gelles, Swelling and dislocation evolution in simple ferritic alloys irradiated to high fluence in FFTF/MOTA, Journal of Nuclear Materials, 225 (1995) 154-162.

[34] S.I. Porollo, A.M. Dvoriashin, A.N. Vorobyev, Y.V. Konobeev, The microstructure and tensile properties of $\mathrm{FeCr}$ alloys after neutron irradiation at $400^{\circ} \mathrm{C}$ to $5.5-7.1 \mathrm{dpa}$, Journal of Nuclear Materials, 256 (1998) 247-253.

[35] C. Capdevila, M.K. Miller, K.F. Russell, J. Chao, J.L. González-Carrasco, Phase separation in PM $2000^{\mathrm{TM}} \mathrm{Fe}-$ base ODS alloy: Experimental study at the atomic level, Materials Science and Engineering: A, 490 (2008) 277-288. 
[36] S. Kobayashi, T. Takasugi, Mapping of $475^{\circ} \mathrm{C}$ embrittlement in ferritic $\mathrm{Fe}-\mathrm{Cr}-\mathrm{Al}$ alloys, Scripta Materialia, 63 (2010) 1104-1107.

[37] E. Meslin, M. Lambrecht, M. Hernández-Mayoral, F. Bergner, L. Malerba, P. Pareige, B. Radiguet, A. Barbu, D. Gómez-Briceño, A. Ulbricht, A. Almazouzi, Characterization of neutron-irradiated ferritic model alloys and a RPV steel from combined APT, SANS, TEM and PAS analyses, Journal of Nuclear Materials, 406 (2010) 73-83.

[38] S. Novy, P. Pareige, C. Pareige, Atomic scale analysis and phase separation understanding in a thermally aged Fe-20at.\%Cr alloy, Journal of Nuclear Materials, 384 (2009) 96-102.

[39] F. Bley, Neutron Small-Angle Scattering Study of Unmixing in FeCr Alloys, Acta Metallurgica Materialia, 40 (1992) 1505-1517.

[40] P. Dubuisson, D. Gilbon, J.L. Seran, Microstructural evolution of ferritic-martensitic steels irradiated in the fast breeder reactor Phenix, Journal of Nuclear Materials, 205 (1993) 178-189.

[41] W.-Y. Chen, Irradiation Damage in Neutron Irradiated FeCr Model Alloys, in: Nuclear Engineering, University of Illinois at Urbana Champaign, Urbana, IL, 2014.

[42] V. Jaquet, Effet de l'irradiation sur la démixtion des alliages

modèles FeCr autour de 15\% de chrome., in, ÉCOLE POLYTECHNIQUE, 2000.

[43] A. Horsewell, B.N. Singh, Influence of Grain and Subgrain Boundaries on Void Formation and Growth in Aluminum Irradiated with Fast Neutrons, in: F. Garner, N. Packan, A. Kumar (Eds.)

Radiation-Induced Changes in Microstructure: 13th International Symposium, American Society for Testing and Materials, 1987.

[44] S. Zinkle, B.N. Singh, Microstructure of $\mathrm{Cu}-\mathrm{Ni}$ alloys neutron irradiated at $210^{\circ} \mathrm{C}$

and $420^{\circ} \mathrm{C}$ to $14 \mathrm{dpa}$, Journal of Nuclear Materials, 283-287 (2000) 306-312.

[45] M.A. Sokolov, H. Tanigawa, G.R. Odette, K. Shiba, R.L. Klueh, Fracture toughness and Charpy impact properties of several RAFMS before and after irradiation in HFIR, Journal of Nuclear Materials, 367-370 (2007) 68-73.

[46] M. Matijasevic, E. Lucon, A. Almazouzi, Behavior of ferritic/martensitic steels after n-irradiation at 200 and $300^{\circ} \mathrm{C}$, Journal of Nuclear Materials, 377 (2008) 101-108.

[47] K.G. Field, R.H. Howard, Y. Yamamoto, Experimental Plan and Irradiation Target Design for FeCrAl Embrittlement Screening Tests Conducted Using the High Flux Isotope Reactor, in, Oak Ridge National Laboratory. 